DOE/NASA/20320-37

NASA TM-82784

\title{
Evaluation of Lightning Accommodation Systems for Wind- Driven Turbine Rotors
}

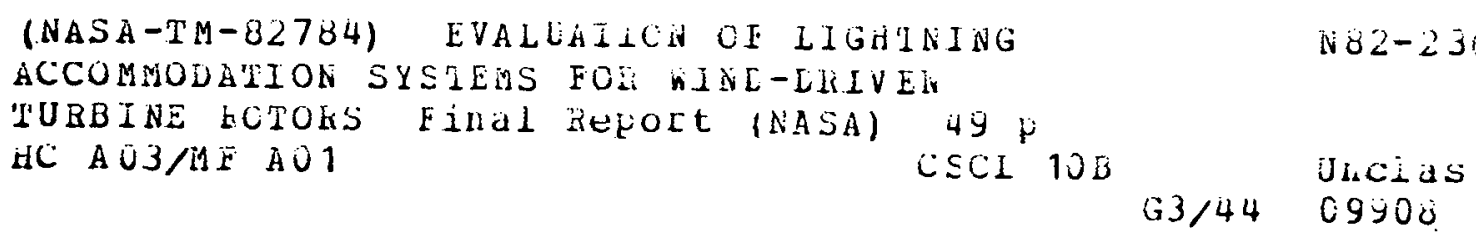

H. Bankaitis

National Aeronautics and Space Administration

Lewis Research Center

March 1982

Prepared for

U.S. DEPARTMENT OF ENERGY

Conservation and Renewable Energy Division of Wind Energy Systems 
NOTICE

This report was prepared to document work sponsored by the United States Government. Netther the United States nor its agent, the United States Department of Energy, nor any Federal employees. nor any of their contractors, subcontractors or their employees, makes any warranty, express or implied, or assumes any legal liability or responsibility for the accuracy, completeness, or usefulness of any information, apparatus, product or process disclosed.. or represents that its use would not infringe privately owned rights.

Trade names or manufacturers' names are used in this report for identification only. This usage does not constitute an of ficial endorsement, either expressed or implied, by the National Aeronautics and Space Administration.

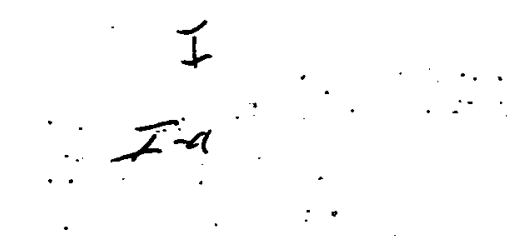


DOE/NASA/20320-37

NASA TM-82784

\section{Evaluation of Lightning Accommodation Systems for Wind- Driven Turbine Rotors}

H. Bankaitis

National Aeronautics and Space Administration

Lewis Research Center

Cleveland, Ohio 44135

March 1982

Work performed for

U.S. DEPARTMENT OF ENERGY

Conservation and Renewable Energy

Division of Wind Energy Systems

Washington, D.C. 20545

Under Interagency Agreement DE-Al01-76ET20320

$$
\text { I. a }
$$




\title{
EVALUATION OF LIGHTNING ACCOMMODATION SYSTEMS
}

FOR WIND-DRIVEN TURBINE ROTORS

\author{
H. Bankaitis \\ National Aeronautics and Space Administration \\ Lewis Research Center \\ Cleveland, Ohio \\ SUMMARY
}

\begin{abstract}
Several concepts of lightning accommodation systems for wind-driven turbine rotor blades were evaluated by submitting them to simulated lightning tests. Test samples representative of epoxy-fiberglass and wood-epoxy composite structural materials were submitted to a series of high-voltage and high-current damage tests. The high-voltage tests were designed to determine the strike points and current paths through the sample and the need for, and the most proper type of, lightning accommodation. The high-current damage tests were designed to determine the capability of the potential lightning accommodation system to sustain the 200-kA lightning current without causing damage to the composite structure.
\end{abstract}

The observations and data obtained in the series of tests of lightning accommodation systems clearly led to the conclusions that compositestruct:iral-material rotor blades require a lightning accommodation system; that the concepts tested prevent internal streamering; and that keeping discharge currents on the blade surface precludes structure penetration. Induced voltage effects or any secondary effects on the integral components of the total system could not be addressed. Further studies should be carried out to encompass effects on the total system design.

\section{INTRODUCTION}

Lightning is a naturally occurring phenomenon that presents a potential danger to ground structures. The Department of Energy's (DOE) research and development efforts in harnessing wind as a potential source of energy by using wind-driven turbine generators involves building structures at those locations with the most consistently present wind conditions. These locations, as illustrated in figure 1, coincide with the most frequent occurrence of lightning activity. Even if the probability of the wind-driven turbine generator structure being hit by lightning is low, the involvement of complex research instrumentation, mechanical hardware, and personnel at these sites warrants the establishment and use of economical and proper lightning accommodation systems. Furthermore, the use of composite structural materials for rotor construction presents a series of unique problems that must be properly addressed and resolved. Resolution of these problems should be verified during the design phase and before committing to manufacturing and field installation. The approach taken to recognize and properly resolve these problems during the design phase was a cooperative effort between the NASA Lewis Research Center, acting as technical manager of the DOE's research and 
development efforts, the blade manufacturer, and recognized experts in the field of lightning research.

The establishment of criteria to be consistently met by a suitable lightning accommodation system was basically influenced by factors encompassing economics, manufacturing, materials, and interference with the environment. The roles of these various factors were then evaluated, and a series of ground rules were established by Lewis. Accordingly candidate lightning accommodation systems for wind-driven turbine generator rotors must be

(1) Capable of dissipating the energy imparted by a lightning strike without deleterious effects to personnel, structure, or instrumentation

(2) Inexpensive to install and maintain

(3) Compatible with the processes by which wind-driven turbine rotor blades are manufactured

(4) Capable of withstanding repeated lightning strikes

(5) Easily repaired in the field

(6) Noninterfering with television reception or navigational or communication equipment functions

In meeting all these requirements the designed system shall not compromise the design weight or arm moment requirements of the rotor blade.

Several concepts were developed by the various manufacturers of compositestructural-material rotor blades and subsequently evaluated by submitting them to simulated lightning current tests. The information refined from these test data is being applied in designing less complex and more effective lightning accommodation systems. In conjunction with this activity, efforts were begun to gather lightning strike energy level data by using the passive lightning current detectors illustrated in figure 2 and fully described in references 1 and 2 .

The information presented in this report is a compilation of the data obtained by various rotor blade manufacturers and lightning researchers under DOE's sponsorship and Lewis' technical management, as reported in references 3 and 4 . In addition, information obtained by private funding but being applied to the wind-driven turbine generator technology is also included (ref. 5).

\section{SIMULATED LIGHTNING TESTS LIMITATIONS}

With respect to simulated lightning tests, several limitations must be clearly understood. The most important limitation is that there is no facility capable of even beginning to fully simulate the complete and simultaneous spectrum of energy and interactions presented by the naturally occurring lightning phenomenon. However, most of the individual voltages and current characteristics known to make up natural lightning can be separately duplicated by existing laboratory generators. Thus, reasonable simulations 
of these individual energy spectrum characteristics are being proficiently achieved, and with expert analysis proper designs of systems capable of accommodating the complete spectrum of natural lightning characteristics can be implemented.

Another important limitation is the extent to which the test sample represents the full-scale production rotor blade. Ideally, the test sample should be a full-scale production rotor blade or a representative prototype because even minor variations from the samples tested may change the behavior of the lightning currents. In the case of wind-driven turbine rotor blades, use of such full-scale hardware is physicaliy as well as economically unfeasible. The size and complexity of the rotor blade design are dictated by the size of the wind-driven turbine generator the rotor must drive. Blade. sizes are illustrated in figure 3. Use of such large test objects would be limited not only by the physical size of the available test facility, but also by the generator capacity. Thus, subscale-model rotor blade samples had to be used in these simulated lightning tests.

Finally, it must be clearly understood that only the rotor blade aspect of interaction with a lightning strike was considered. The grounding of the tower, protection of the bearings, or effects on instrumentation and any potential interactions between these various interfaces were considered to be outside the scope of these simulated lightning tests and not within the scope of the blade lightning accommodation system design objective. Thus, verification of the total wind-driven turbine lightning accommodation system was not undertaken.

\section{DESIGN AND TEST OBJECTIVES}

The lightning accommodation system concepts for use with compositestructural-material blades were based on the objectives of preventing the lightning strike's electrical components and the accompanying energies from penetrating the composite material structure and also preventing any internal streamering, as illustrated schematically in figure 4.

The primary reason for these objectives, because of the highly dielectric properties of composite-structural-material rotor blades, is to avoid the possibility of lightning puncture to the blade interior. Subsequent lightning arc pressures in the interior of the blade could cause hoop stress of sufficient magnitude to structurally destroy the blade. Such an occurrence could begin by the generation of internal streamering, which would provide an internal ground point for the approaching lightning step leaders. The methods to provide conductive paths, and hence lightning accommodation systems, for the blade were individually developed by the manufacturers of compositestructural-material rotor blades in consultation with expert lightning researchers. In this manner these individually chosen systems were compatible with the manufacturers' rotor blade designs and the respective proprietary blade fabrication processes. Thus, before a particular lightning accommodation system was accepted as being valid, it was verified by the simulated lightning tests. 


\section{SIMULATED LIGHTNING PARAMETERS}

Lightning parameters that can be individually simulated in a laboratory fall into two general categories: the high voltages produced during the lightning strike, and the currents that flow in the completed channel of lightning. The high-voltage characteristics were used to determine attachment points, breakdown paths, and streamer effects. These characteristics were attained by using steep-front voltage waves $(1000 \mathrm{kV} / \mu \mathrm{s} \pm 50 \%)$. The voltage waveform is illustrated in figure 5 , and in general was in accoraance with procedures described in the SAE Committee AE4L Report (ref. 6). Not all the requirements and tests outlined in this reference were applicable to the winddriven turbine rotor blade tests, but selective test waveforms and procedures were adopted for the needs of each set of tests. The faster wavefronts were used for testing dielectric materials because according to information in reference 6 such a waveform presents a greater probability of puncture.

The high-current flow characteristics were simulated for damage tests and to check the capability of the accommodation system to withstand the lightning currents. The applied currents ranged in excess of $200 \mathrm{kA}$. Severe limitations of current inherently resulting from tests of large objects with large path inductance necessitated that high current tests be performed locally at the most critical tip and root areas of the rotor blade or representative small specimen.

\section{TEST FACILITIES}

The tests were conducted by two distinguished companies at their respective test facilities. One of the companies was Lightning and Transients Research Institute with test laboratories at St. Paul, Minn., and Miami Beach, Fla. J. D. Robb was their principal investigator. The other company was Lightning Technologies, Inc., who used the test facilities of the General Electric High Voltage Laboratory in Pittsfield, Mass. Keith Crouch was their principal investigator.

The facilities were equipped with the proper impulse- and currentgenerating equipment, capacitance banks, and photographic as well as currentmonitoring instrumentation. These facilities are suitably detailed in the discussions of individual test procedures and data in subsequent sections of this report as well as in references 3 and 4 .

\section{TEST SAMPLES}

The candidate designs of rotor blades for wind-driven turbine generator applications are based on the use of two types of composite structural materials: an epoxy-fiberglass material, and an epoxy-wood material. These composite materials have many attractive characteristics from the viewpoint of structural and economic considerations. However, the highly dielectric properties of the blade materials enhance the need for proper lightning accommodation systems. In turn these systems must be compatible with the rotor blade designs they must serve. 
In general the test samples representative of the two types of composite structural materials consisted of a full-scale chordwise dimension of the rotor blade and 4.6- to 6.1-m span with appropriate simulation of the steel hub adapter at the root end. The test sample representative of the epoxyfiberglass materials was manufactured by Kaman Aerospace and is illustrated in figure 6 . The test sample was a 4.6-m-span rotor blade section consisting of an all-fiberglass D-spar, an afterbody of fiberglass-faced-paper honeycomb panels, and a steel hub adapter installed at the inboard end of the spar. The wall thickness of the hollow D-spar was approximately $2.5 \mathrm{~cm}$, and the afterbody panels consisted of 5-cm-thick honeycomb core panels with 15-mm-thick epoxy-fiberglass skins. There were no metal parts inside the test sample. However, the sample was stored and then transported from Connecticut to the Florida test site unprotected from environment and as a result was thoroughly soaked by rain. It was used in the "as is" condition during the initial 27 exposures in the high-voltage, long-arc tests.

The test sample representative of the wood-epoxy composite structural material is shown in figure 7. The sample was a 6-m span with an all-wood laminate D-spar and plywood-sandwiched 5.1-cm-thick honeycomb core tail panels. The wood laminate D-spar was approximately $3.8 \mathrm{~cm}$ thick. The outer surface of the sample was covered with 0.13-mm-thick epoxy-soaked fiberglass cloth. An aluminum rod approximately $1.8 \mathrm{~m}$ long was installed along the inside of the leading edge of the D-spar to simulate internal wiring or other metallic components. This rod was retained in the test specimen throughout the test sequence. For the high-current damage test a $61-\mathrm{cm}$ by $61-\mathrm{cm}$ square plywood Nomex sandwich panel, as illustrated in figure 8 was used. Aluminum screen was bonded under a $0.13-\mathrm{mm}$-thick layer of fiberglass cloth.

\section{EPOXY-FIBERGLASS TESTS}

This series of tests were conducted by Lightning and Transients Research Institute on the Kaman Aerospace sample illustrated in figure 6 and described in the section TEST SAMPLES.

\section{FIRST SET OF HIGH-VOLTAGE TESTS}

These tests consisted of a series of high-voltage (3.5 MV, 20 kA), longarc simulated discharges on the sample. Because these electric currents were of sufficiently low magnitude to impart only nominal damage to the test sample, repeated tests could be performed and lightning accommodation schemes systematically introduced.

The objectives of this particular series of tests were threefold: first, to determine the strike points and current paths through the sample from the tip to the root end attachment; second, and probably equally important, to determine whether lightning accommodation provisions are indeed necessary for composite material rotor blades; and third (if lightning accommodation provisions are needed) to determine the lightning accommodation system most proper for the particular blade design.

The test sequence was begun by submitting the sample to long-arc discharge without any lightning accommodation provision and monitoring the blade spar 
interior by a camera through a mirror, as illustrated in figure 9 . The test sequence is illustrated in the individual photographs in figures 10 to 16 . These initial strikes did puncture the tip and penetrate the blade interior as shown in figures $10(a)$ and (b). Additional strikes imparted on the test sample at various locations on the tip exhibited stitching in and out through the aft paneis from tip to root. These are illustrated in figure 11.

Partial penetration through the interior of the trailing-edge box is shown in figure 12. Had these discharges been high-current natural lightning strikes, catastrophic structural damage would most likely have ensued. Thus a lightning accommodation system is required for this particular type of rotor blade structure.

A lightning accommodation system was installed in stages and submitted to subsequent high-voltage attachment tests in order to determine the minimum configuration required to eliminate internal streamering. A succession of top-surface conductors was added and tested until no further streamering or stitching was observed.

A full-chord metal cap was simulated by adding aluminum foil to form a 7.6-cm skirt inboard of the tip of the blade and was submitted to the highvoltage discharge. The discharge struck the foil cap and propagated over the exterior path along the afterbody. Moreover, it eventually penetrated the afterbody in areas away from the blade tip, as shown in figure 13.

Next two chordwise strips of foil were added at approximately 1.2-m intervals across the afterbody to provide external conductive paths in an attempt to help in establishing the arc completely over the exterior surface. However, penetrations of the afterbody were still observed, as evidenced in figure 14. This penetration may have been due to moisture in the test sample or the many puncture paths from previous tests.

A full-span conductor (aluminum foil connecting to the chordwise strips already in position) was added down the trailing edge of the test sample, and an additional chordwise strip was placed along the bottom over to the spar. As shown in figure 15 the discharge current apparently was satisfactorily carried by the current paths provided by the foil strips and the tip cap without any further penetration of the spar or the afterbody panels.

The final sequence of high-voltage attachment tests was carried out on the test sample containing just the tip cap, one chordwise strip approximately two-thirds of the way to the root end, and the trailing-edge down-conductor. Puncture to the interior is evidenced by the discontinuous surface arc shown in figure 16. It may be concluded from these observations that the punctures occurred in the relatively thin afterbody panels. Penetration of the leading D-spar edge of the blade was precluded by its thickness, and the energy characteristics of the high-voltage, long-arc discharges were not of proper magnitude to cause puncture of the leading edge of the rotor blade.

The initial conclusions to be drawn from this series of tests are as follows: 
(1) A lightning accommodation system is required for this type of composite-structural-material blade especially at the tip, the trailing edge, and the root end to assure that discharges are retained on the exterior surfaces.

(2) The need for a leading-edge conductor was not clearly demonstrated.

\section{First Set of High-Current Damage Tests}

The test specimen with the aluminum foil placement, shown in figure 17, was repositioned horizontaliy for high-current damage tests. The objectives of this series of tests were to determine the capability of the potential lightning accommodation system (fig. 17) to sustain the 200-kA lightning current and, more importantly, to determine whether the discharge would be dissipated along the conductive paths without causing damage to the composite structure.

The first task in this series of tests was to calibrate the high-current generator. This was done by firing a low-level current into the test sample to determine the charge voltage needed to reach the required current. The current generator measurements were checked by calculating the theoretical current from the known bank capacity, charge voltage, and oscillatory decrement and period as determined from waveform oscillograms. The exact circuit equations were solved on a computer, but a simplified solution (ref. 3 ), which is usually sufficiently accurate, can be derived by using the following equation:

$$
i_{\max }=\frac{v c 2 \pi}{t} \cdot \sqrt[4]{d_{2} / d_{1}}
$$

where

$\begin{array}{ll}i_{\max } & \text { maximum current, } A \\ v & \text { charge voltage, } v \\ c & \text { bank capacity, } \mu \mathrm{F} \\ \mathrm{t} & \text { period, } \mu \mathrm{s} \\ \mathrm{d}_{1} & \text { first half peak } \\ d_{2} & \text { second half peak }\end{array}$

The calibration results (ref. 3) together with the Pearson probe measurements are presented in table I.

A selective high-current oscillogram is shown in figure 18 . Normally when the theoretical calculations and measured currents agree to within about 5 to 10 percent, the calibration is considered acceptable. For the purposes of these tests the values as shown in table I were considered acceptable even though they exceeded the 5 to 10 percent range.

The high-current tests demonstrated that the provided paths would successfully carry the current without damage to the composite structure even though the thin aluminum foil used in this series of tests for ease of configuring could not withstand repeated strikes. The required $200 \mathrm{kA}$ could not be dis- 
charged through the full length of the test specimen because of the large inductance, which limited the maximum current. But on the other hand such a high current represents a strike level that occurs less than 1 percent of the time. The damage incurred by the foil is shown in figure 19. The damage was very local and, if such a system were to be used on operational wind-driven turbine blades, the damage could be easily repaired in the field.

\section{Conclusions Based on First Test Series}

This sequence of tests demonstrated

(1) That to prevent internal streamering in the composite-structural-material blade a lightning accommodation system is required

(2) That a network of surface paths can successfully accommodate excessively high currents without significant damage to the structure

(3) That the extensiveness of the need for a network of current paths has not been adequately defined and further work is necessary

(4) That the 200-kA capability may be a commendable objective but, on the basis of the rarity of occurrence of this strike level, may be an overambitious objective

Based on the data and observations of the described tests, Kaman Aerospace set about to derive a lightning accommodation system that would be a more durable and more production-representative concept. The concept consisted of a trailing-edge down-conductor of flat; braided-copper-wire cable coated with thermoplastic; a full-chord tip cap of aluminum; and Hexcel Thorstrand covering the blade root area. The cross-sectional area (MIL-W-3861) of the flat, braided cable was 48000 circular mils. On the basis of data in readily available literature this circular cross-sectional area was judged to be able to accommodate the lightning strike current of the levels pertinent to this application as well as the ensuing thermal effects. In addition, the cable weight for a 30.5-m-long Mod-1 type rotor blade would be $7.3 \mathrm{~kg}$. The thermoplastic coating was used to minimize the axial stiffness mismatch between the conductor and the fiberglass composite and also to guard against corrosion or other undesirable effects by the environment. Thorstrand is Hexcel's trade name for a woven cloth of aluminized glass fibers. This material was submitted to simulated lightning tests, and the results are described by J. A. Plumer in reference 7. Thorstrand was placed at the blade root area shield the steel internal hub adapter against lightning penetration through the composite material structure to the adapter. To minimize television interference, chordwise conductors were excluded. The concept is illustrated in figure 20.

The simulated lightning tests of the concept were conducted by using the previously described test specimen and test procedure with one exception. Before the tests with the rotor blade specimen samples of glass-fiber-wrapped, plastic-coated flat cable were tested at currents to $200 \mathrm{kA}$ at the Lightning and Transients Research Institute's St. Paul, Minn., facility without any significant distortion being reported. 
Second Set of High-Voltage Tests

The test specimen with the lightning accommodation system described previously and illustrated in figure 20 was submitted to high-voltage, long-arc simulated lightning strokes. The objective was to identify lightning discharge current paths on the sample. In all cases except one, the simulated lightning stroke attached to the surface and dissipated across it to either the aluminum tip cap, the trailing-edge conductor, or the root end. The exception occurred in test 2, during which the probe was located $2.9 \mathrm{~m}$ from the root end at the leading edge of the D-spar. The arc attached at $2 \mathrm{~m}$ from the root end and $48 \mathrm{~cm}$ aft of the leading edge. The afterbody puncture (entry point) was $76 \mathrm{~cm}$ from the arc attachment point, and the exit point was $86.4 \mathrm{~cm}$ from the arc attachment point. Surface flashover completed through the remainder of the surface to the root of the sample. No attachments were observed on the leading-edge D-spar. All attachment points were either on the afterbody (tail panels) or on one of the current paths (conductors), as indicated by the carbonaceous trail line in figure 21.

Second Set of High-Current Damage Tests

The second set of high-current damage tests proved to be more venturesome. The test setup (fig. 22) and currents were within the desired calibration range and magnitude, as in the first set of high-current damage tests. In the first test of the second set of high-current damage tests a strike on the tip cap discharged a 229-kA current along a 51-cm-long section of the flat, braided cable fastened to the rotor blade test specimen surface with contact cement. The 51-cm-long section of cable was blown off, as shown in figure 23. The resuit was very surprising to the personnel present at the test site. The primary cause of the outcome was the electromagnetic force produced by the abrupt direction change in lightning current flow. In setting up for the test we had overlooked the need to insure that the radius of bend of the conductor was not less than $20.3 \mathrm{~cm}$ even though the angle was not less than $90^{\circ}$ (ref. 8). The most unexpected result was the catastrophic failure of the down-conductor (i.e., the curling and excessive distortion of the flat, braided cable). Previous test reports had stated that currents of such magnitude were successfully carried without any significant distortion. Review of the observations with the author of these reports disclosed that the same type of distortion had been observed and judged not to be significant. Such a judgment by itself may not be improper. However, in light of the total rotor blade structure and the cable being an integral part of the structure, the distortion as experienced becomes a source of concern. Specific concerns are potential irreparable structural damage to the rotor blade or irreparable damage only to the down-conductor that would require replacement of the total lightning accommodation system. Either occurrence would result in extensive machine downtime and exorbitant repair costs.

To more fully define the susceptibility of a flat, braided cable to distortion as a function of current level, five high-current shots of progressively higher current levels were fired at the 78.7-cm-long braided-cable specimen. The cable specimen was located on the trailing edge of the rotor blade specimen in such a manner as to reduce the abruptness of changes in current flow direction and thus reduce electromagnetic force effects, as shown 
in figure 24. None of the strokes caused damage to the rotor blade sample. The current levels through the braided cable and the observed cable condition are given in table II.

The aftermath of the last current shot in table II is illustrated in figure 25. Note that a goodly portion of the braided cable is missing (right side of the figure) and the remainder is badly distorted.

A single 217-kA strike was impacted onto a 15.2-cm-wide strip of Thorstrand bonded to the afterbody of the test specimen. There was no damage to the test specimen. The Thorstrand, however, sustained irreparable damage. The aluminized coating on the glass fibers parallel to the current flow was vaporized and thus rendered ineffective for subsequent strikes.

\section{Conclusions Based on Second Test Series}

The lightning accommodation system configuration consisting of the aluminum tip cap and the flat, braided cable down-conductor located on the trailing edge of the rotor blade and grounded to the metal adapter will be adequate for numerous lightning strikes of 150-kA current levels. However, several consecutive 150-kA strikes might cause field-repairable damage to the system. Lightning strikes imparting current levels exceeding $150 \mathrm{kA}$ and reaching $200 \mathrm{kA}$ most likely would cause damage requiring more extensive repairs. The extent of damage and the definition of needed repairs could not be ascertained during these tests.

\section{EPOXY-WOOD TESTS}

This series of tests were conducted by Lightning Technologies, Inc., at the General Electric High Voltage Laboratory in Pittsfield, Mass., on the Gougeon Brothers sample illustrated in figure 7 and described in the section TEST SAMPLES.

\section{High-Voltage Tests}

The low-power-level tests were to be performed first on the test specimen containing no lightning accommodation system

(1) To identify complete external lightning current paths, including those resulting from side flashes

(2) To determine the current paths if the interior of the blade contained cables, hydraulic lines, strain gages, or navigational lightning wiring

These low-power tests were to be used as the basis for defining and testing the proper prototype concept of a lightning accommodation system.

The test specimen as manufactured was not equipped with any type of lightning accommodation system. To assure that the test specimen was not rendered useless before the intended tests were completed, the sequence of Lightning Technologies' recommendations was reversed. Gougeon Brother, on J. D. Robb's recommendation, were using total rotor blade surface coverage 
with aluminum screen as a lightning accommodation system. The approach was economical and very compatible with the manufacturing process. Thus the test sequence was started with the test sample being equipped with aluminum screen surface coverage as the lightning accommodation system. The accommodation system was progressively diminished until there was none for the final series of shots. The progression is schematically illustrated in figure 26.

Instrumentation. - A Marx type of impulse generator was used in the highvoltage attachment test. A circuit schematic is illustrated in figure 27 (ref. 4). A high-impedance, compensated voltage divider was used to monitor applied test voltages. The output waveform was displayed on a Tektronix 507 oscilloscope. The steep-front waveforms were in accordance with the characteristics described reference 6 .

Sequence of tests. - Sixteen high-voltage attachment tests were conducted. Of these, 11 were positive polarity tests and 5 were negative polarity tests. Test results are summarized in table III (data from ref. 4) and shown in figures 28 to 37 .

The series of tests listed in table IlI were carried out in distinct groups. The first group consisted of tests 2 and 3 . For this group of two shots the test electrode was positioned at the leading edge of the test specimen approximately $2.5 \mathrm{~m}$ down from the tip. The test specimen was protected by aluminum screen except at the leading edge, where an approximately 31-cm gap between the aluminum screens exposed unprotected surface. As noted in table III, attachment was to the screen. For the next group of tests $(4,5$, and 6 ) the test electrode was moved to the center of the leading edge and closer to the unprotected leading-edge surface. All shots attached to the screen.

The third group of tests ( 7 to 11 ) were negative polarity shots (fig. $32(a))$, and all attached to the screen once the specimen and electrodes were properly positioned. The remaining group of tests (12 to 15) were carried out with an aluminum tip cap and a 1.3-cm-wide aluminum tape conductor down the trailing edge of the specimen. At test 12 puncture was evident. Polaroid cameras were installed in the D-spar and in the afterbody (wing box) to record internal streamering, and the test was repeated (test 13). There was no evidence of streamering in the afterbody. D-spar streamering was evident from the grossly overexposed film strip. Neutral density filters were installed on the D-spar camera lens and the test was repeated (test 14) (fig. 37(a)). The specimen was punctured again. There was no evidence of streamering in the afterbody. Inside the D-spar the streamer traveled down the inside leading edge and attached to the aluminum bar conductor, simulating internal wiring as illustrated in figure $37(b)$. For test 15 in this group the specimen was rotated $90^{\circ}$, as shown in figure 35 , and the electrode was positioned half-way between the leading edge and the afterbody to determine if the charge would stay on the surface and reach the aluminum tape down-conductor. The side was punctured. The streamer went along the inside surface of the afterbody, penetrated the D-spar, and came down through the aluminum bar conductor along the inside surface of the leading edge, as illustrated in figures 4 and 38 . The last shot (test 16) was made on the test specimen without any conductive paths on the surface. The attachment occurred at the top of the test specimen, punctured it, and went down the inside of the leading edge. There was no 
evidence of streamering in the afterbody, only in the D-spar, as seen in figure 39. The expectation was that the specimen would be destroyed by such a shot, but it did not happen.

After the test specimen was returned to Lewis, it was dissected at the points of puncture. The evidence of arc penetration through the epoxy-wood structure is shown in figures. 40 and 41 . It is interesting to note that the carbonaceous trail of penetration ends at the internal surface of the wall. No other trace of the carbonaceous arc trail could be found.

\section{High-Current Damage Test}

A captive discharge generator, shown in figure 42 (ref. 4), was used for the high-current damage test. The high-current waveform shown in figure 43 was monitored with a wide-band-pulse current transformer rated at $250 \mathrm{kA}$, a current-time product of 64 As with a frequency response of $1 \mathrm{~Hz}$ to $100 \mathrm{MHz}$. The ferrite core had a 100-turn secondary winding terminated in a lowinductance coaxial resistor of $0.01 \Omega \pm 0.1$ percent. The voltage across the resistor was carried by a double-shielded coaxial cable to a type 7704A Tektronix osilloscope housed in a shielded room.

The specimen for this test consisted of a $61-\mathrm{cm}$ by $61-\mathrm{cm}$ square plywood Nomex sandwich panel with aluminum screen bonded under a 33-mm-thick layer of fiberglass. The specimen panel was installed in the high-current generator with about a 3-cm electrode gap ( $f$ ig. 8). A 210-kA pulse with an action integral of $3.5 \times 10^{6} A^{2} \mathrm{~s}$ was applied to the specimen. As shown in figure 44 the aluminum screen and fiberglass coating evaporated or blew off in a 76-mmradius circle under the entry point and the fiberglass peeled in other areas and delaminated from the Nomex honeycomb. No further major structural damage was evident. The damaged area could be easily repaired in the field.

Hamilton Standard, a division of Uniteo Technologies, funded a test program carried out by Lightning and Transient Research Institute, with 3. D. Robb as the principal investigator (ref. 5). The test program objective was to confirm that the system evolved by Hamilton Standard would properly accommodate current flows and energies from lightning strikes without compromising the epoxy-fiberglass rotor blade structure. Their system uses $153-\mathrm{mm}$ by $0.20-\mathrm{mm}$ adhesive-backed aluminum foil tapes. The test progran successfully verified the acceptability of the Hamilton Standard concept, and by the same token verified the observation and findings of the test prograns carried out under Lewis' sponsorship.

\section{CONCLUSIONS AND RECOMMENDATIONS}

The observations and data obtained in series of tests of lightning accommodation systems clearly led to the following general conclusions:

1. Composite-structural-material rotor blades require a lightning accommodation system whether or not the blades contain internal wiring or metallic components. 
2. The basic lightning accommodation concepts examined in these series of tests do effectively contain the charge on the surface of the rotor blade and prevent internal streamering. An aluminum screen covering effectively prevents internal streamering even with a metal conductor component inside the specimen.

3. Adhesive-backed aluminum tape $(153 \mathrm{~mm}$ by $0.20 \mathrm{~mm})$ properly accommodates currents in excess of $200 \mathrm{kA}$ without structural damage to the compositematerial rotor blade, and only very local damage to the tape itself. The local damage at the point of attachment would be easily repairable at very low cost.

4. Keeping discharge currents on the rotor blade surface, specifically by using conductive paths, precludes structure penetration.

5. A conductive tip cap electrically bonded to the current path downconductor is mandatory to preclude lightning entry. into the spar and afterbody from the blade tip.

6. Abrupt direction changes of the current paths must be avoided.

7. Although quantitative data were not obtained, it is known that moisture content in the structure enhances structure penetration by lightning currents.

8. The need to shield internal steel adapters from potentially causing internal streamering between themselves and the tip cap over the length of the internal cavity of the rotor blade has not been clearly substantiated.

9. Induced voltage effects or any secondary effects on instrumentation, structures, or components cannot be assessed.

10. Compliance of the potential lightning accommodation systems with noninterference with television reception has not been defined.

For a lightning accommodation system to be effective, namely to prevent or minimize damage, the system must be capable of accommodating a wide range of lightning currents. One of the most important parameters affecting the damage that may be caused by lightning is the peak current amplitude. From the data published in NASA Reference Publication 1008 (pp. 21, 27, and 28), the probability is that in 50 percent of the strokes the peak current will be greater than $20 \mathrm{kA}$; in 4 percent, greater than $100 \mathrm{kA}$; and in 0.8 percent, greater than $200 \mathrm{kA}$. Combining these data with the isokeraunic level and flash density values (flashes per square kilometer per thunderstorm days per year) indicates that in 10 years only 5 percent of strikes would exceed $100 \mathrm{kA}$ and in 5 years 10 percent of strikes would exceed $65 \mathrm{kA}$. On the basis of these current levels a much simpler lightning accommodation system would be justifiable. One drawback is that while the observed peak current amplitude statistical data may be more predictable, the isokeraunic level data are of limited value. The isokeraunic data do not distinguish between cloud-to-cloud discharges and cloud-to-ground flashes, do not allow for the duration of the storm, and so on. Nevertheless, it would seem that a lightning accommodation system capable of handling 100- to 150-kA peak current amplitude would still 
be effective even for a 200-kA stroke. However, a system having experienced such a peak current amplitude undoubtedly would have to be repaired.

An effective, yet simple, lightning accommodation system would consist of an aluminum tip.cap with an electrically bonded down-conductor on the trailing edge of the rotor blade grounded to the steel hub adapter and chordwise strips of current diverters from the leading edge to the trailing-edge down-conductor every 1.5 to $2 \mathrm{~m}$ of the rotor b.lade spar. Use of the current diverters has been described by Plumer and Hoots (ref. 10).

The effects discussed in this report emphasize lightning accommodation systems for rotor blade structures only. However, mechanical components, tower structure, generating equipment, instrumentation, and electronic components must be included in the total system design. Building structures and generator equipment without specific and proper provisions to accommodate currents from a lightning stroke may have most undesirable consequences. The bearings may be rendered irreparable or their lifetimes may be considerably reduced. Development of induced voltages in instrumentation lines located in the tower structure or interfacing with utility power lines can cause extensive damage to instruments, sensors, microprocessors, computers, and control circuits. The consequences of these damages can range from a totally uncontrollable machine or unpredictable response to commands to total disfunction of the operating system. An additional hazard is presented by field repairs or in field modifications such as installation of ice detectors, tip weights, and additional instrumentation. The real danger is that such actions may compromise a properly designed lightning accommodation system and render it ineffective.

There are no recorded data of a wind-driven turbine generator structure being hit by lightning. Even where visual observations have been made, the current peak amplitude of such an "observed" strike is unknown. Therefore designing a lightning accommodation system is more difficult.

To ease the design tasks and to assure that the lightning accommodation systems are properly designed and perform as intended, a dual-activity approach is most strongly recommended. One activity presently pursued is to gather data of lightning strikes on active wind-driven turbine generators and to develop a handbook of recommended procedures for lightning strike accommodation systems on operational wind-driven turbines. This activity is being pursued through a cooperative agreement with Southern Illinois University. Passive lightning current detectors and strategically placed cameras have been installed at the Rocky Flats, Colorado, test site. Site personnel have been acquainted with the need to record occurrences, damages, observations, effects, and delayed effects and to transmit the information to Southern Illinois University and/or the Lewis Research Center. Southern Illinois University collates and analyzes the data, investigates damaged facilities, and documents the findings. These findings, together with appropriate recommendations in conjunction with existing practices and methodology, are being combined into a handbook of acceptable practices for wind-driven turbine systems.

The second activity, namely total system subscale-model testing, if carried out in conjunction with the SIU efforts would be extremely pertinent 
and productive. Conducting a scale-model wind-driven turbine generator system study in a simulated lightning environment would yield data on the basis of an integrated total system rather than piecemeal. Integration of the subscalemodel analysis data with the lightning current detector data would form a very sound technical base for defining more appropriate, realistic, and economically feasible lightning accommodation system designs for wind-driven turbine generators.

\section{REFERENCES}

1. Livermore, Stephen: Development of Lightning Current Detector. NASA TM $X-74154,1976$.

2. Crouch, K. E.: Calibration Tests on Magnetic Tape Lightning Current Detectors. NASA CR-3270, 1980.

3. Robb, J. D.: Lightning Tests of Kaman Composite Wind Turbine Blade Specimen. Report No. 704, Lightning and Transients Research Institute, 1980.

4. Crouch, K. E.: Lightning Strike Tests on a Wooden Wind Turbine Generator Blade. Report LT-80-69, Lighting Technologies, Inc., 1980.

5. Matthews, P. A.: WTS-3 Lightning Test Final Report. HSER 7789 Rev. A, Hamilton, Ltd., 1980.

6. SAE Committee AE4L: Lightning Test Waveforms and Techniques for Aerospace Vehicles and Hardware. Society of Automotive Engineers, Inc., 1978.

7. Plumer, J. A.: Simulated Lightning Tests on Graphite Laminates Protected with Thorstrand Aluminized Glass Cloth. Lightning Technologies, Inc., 1979.

8. Lightning Protection Code 1977, No. 3-15. National Fire Protection Association, 1977, p. 23.

9. Fisher, F. A.; and Plumer, J. A.: Lightning Protection of Aircraft. NASA RP-1008, 1977

10. Plumer, J. A.; and Hoots, L. C.: Lightning Protection with Segmented Diverters - for Aircraft Radomes and Dielectric Structures. Proceedings of the International Symposium on Electromagnetic Compatibility, IEEE 1978, pp. 196-203. 
TABLE I. - HIGH-CURRENT CALIBRATION

\begin{tabular}{|l|r|r|r|}
\hline & Hub area & Full length & Tip area \\
\hline Charge voltage, V & 14000 & 14000 & 14000 \\
Bank capacity, $\mu F$ & 610 & 610 & 610 \\
Period, HS & 230 & 300 & 320 \\
First half peak & 1.75 & 1.3 & 2.3 \\
Second half peak & 0.35 & 0.3 & 0.3 \\
Maximum current, imax, A: & & & \\
Computer calculation & 174000 & 136000 & 118000 \\
Simplified calculation & 156015 & 123968 & 100771 \\
Pearson probe measurement & 199520 & 118000 & 104880 \\
\hline
\end{tabular}

TABLE II. - PROGRESSIVELY HIGHER CURRENT FLOWS

THROUGH BRAIDED CABLE

\begin{tabular}{|c|c|}
\hline$\underset{A}{\text { Current, }}$ & Observed cable condition \\
\hline $\begin{array}{rr}50 & 000 \\
83 & 000 \\
133 & 000 \\
181 & 000 \\
246 & 000\end{array}$ & $\begin{array}{l}\text { No damage } \\
\text { Slight tubular curling } \\
\text { More pronounced tubular curling but no breakage } \\
\text { Complete curling and slight shredding } \\
\text { Braid torn loose and shredded }\end{array}$ \\
\hline
\end{tabular}


TABLE III. - RESULTS OF HIGH-VOLTAGE TESTS ON EPOXY-WOOD BLADES

\begin{tabular}{|c|c|c|c|c|c|}
\hline Test & Polarity & $\begin{array}{c}\text { Pulse, } \\
\text { kV }\end{array}$ & $\begin{array}{c}\text { Wavef ront } \\
\text { rise time, } \\
\mathrm{kV} / \mathrm{ms}\end{array}$ & Observations & Figure \\
\hline $\begin{array}{r}1 \\
2 \\
3 \\
4 \\
5 \\
6 \\
7 \\
8 \\
9 \\
10 \\
11 \\
12 \\
13 \\
14 \\
15 \\
16\end{array}$ & $\begin{array}{l}\downarrow \\
+ \\
+\end{array}$ & $\begin{array}{l}1445 \\
1500 \\
1500 \\
(\text { a) } \\
1420 \\
1420 \\
1490 \\
1490 \\
1510 \\
1500 \\
1500 \\
1700 \\
1730 \\
1680 \\
1480 \\
1975\end{array}$ & $\begin{array}{r}1300 \\
1300 \\
1300 \\
(a) \\
1300 \\
1300 \\
1200 \\
1\end{array}$ & $\begin{array}{l}\text { Generator checkout OK } \\
\text { Attached to screen } \\
\text { Did not cross rod gap } \\
\text { Did not cross rod gap } \\
\text { Attached to screen } \\
\text { Attached to screen } \\
\text { Attached to screen } \\
\text { Punctured leading edge } \\
\text { Punctured leading edge } \\
\text { Punctured leading edge } \\
\text { Punctured side } \\
\text { Punctured }\end{array}$ & $\begin{array}{l}28 \\
\overline{29} \\
30 \\
-- \\
31 \\
-- \\
-- \\
-- \\
32(b) \\
33 \\
34 \\
-- \\
37(a) \\
35 \\
36\end{array}$ \\
\hline
\end{tabular}

ano oscillogram. 


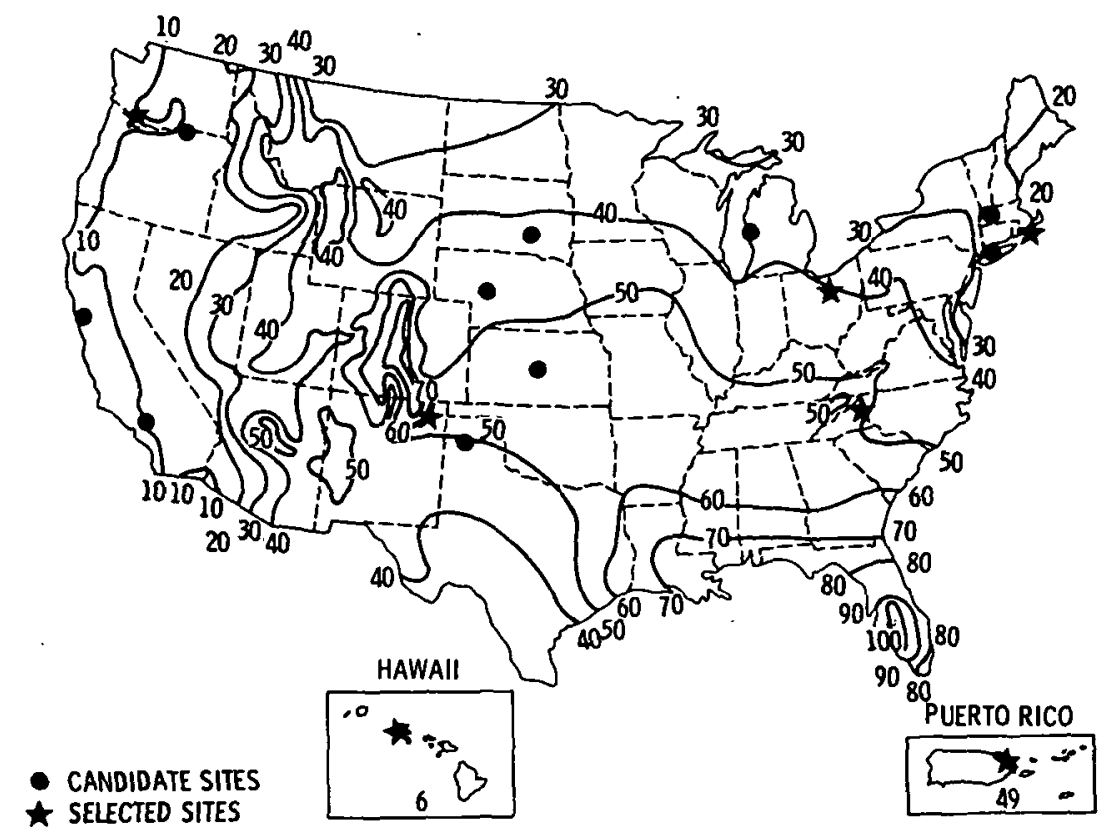

Figure 1 - Isokeraunic map of United States, showing mean annual number of thunderstorm days.

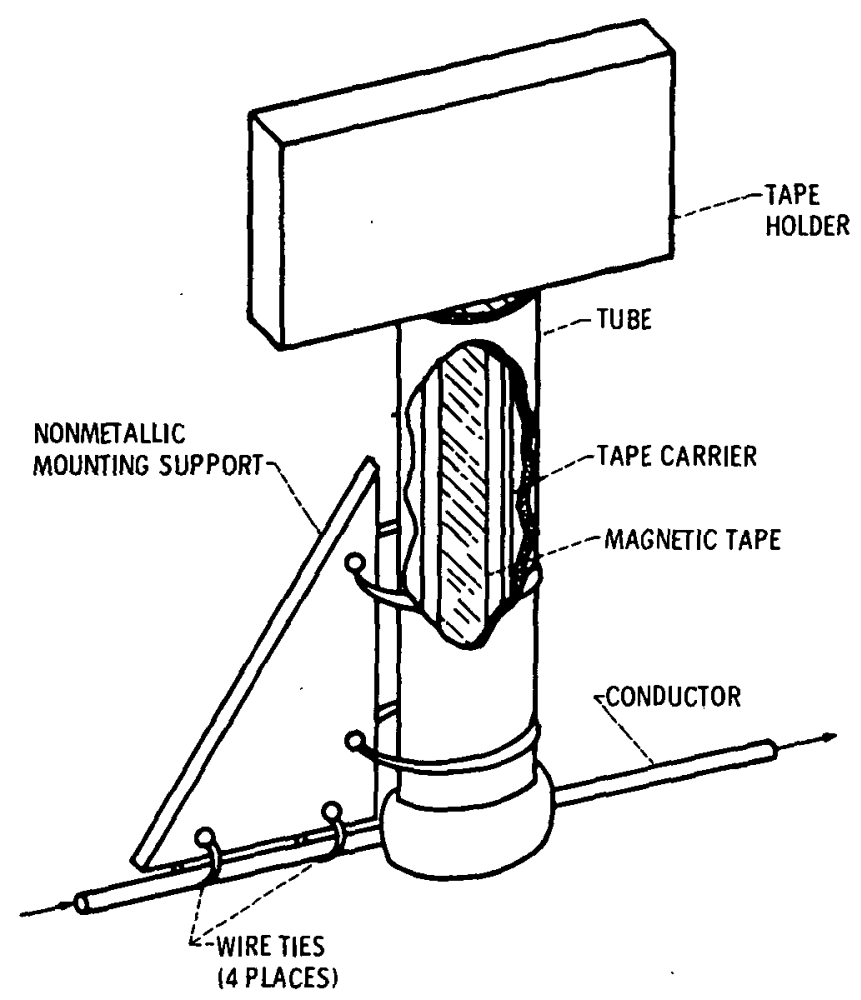

Figure 2 - Typical LCD mounted on conductor. (From ref. 2.) 


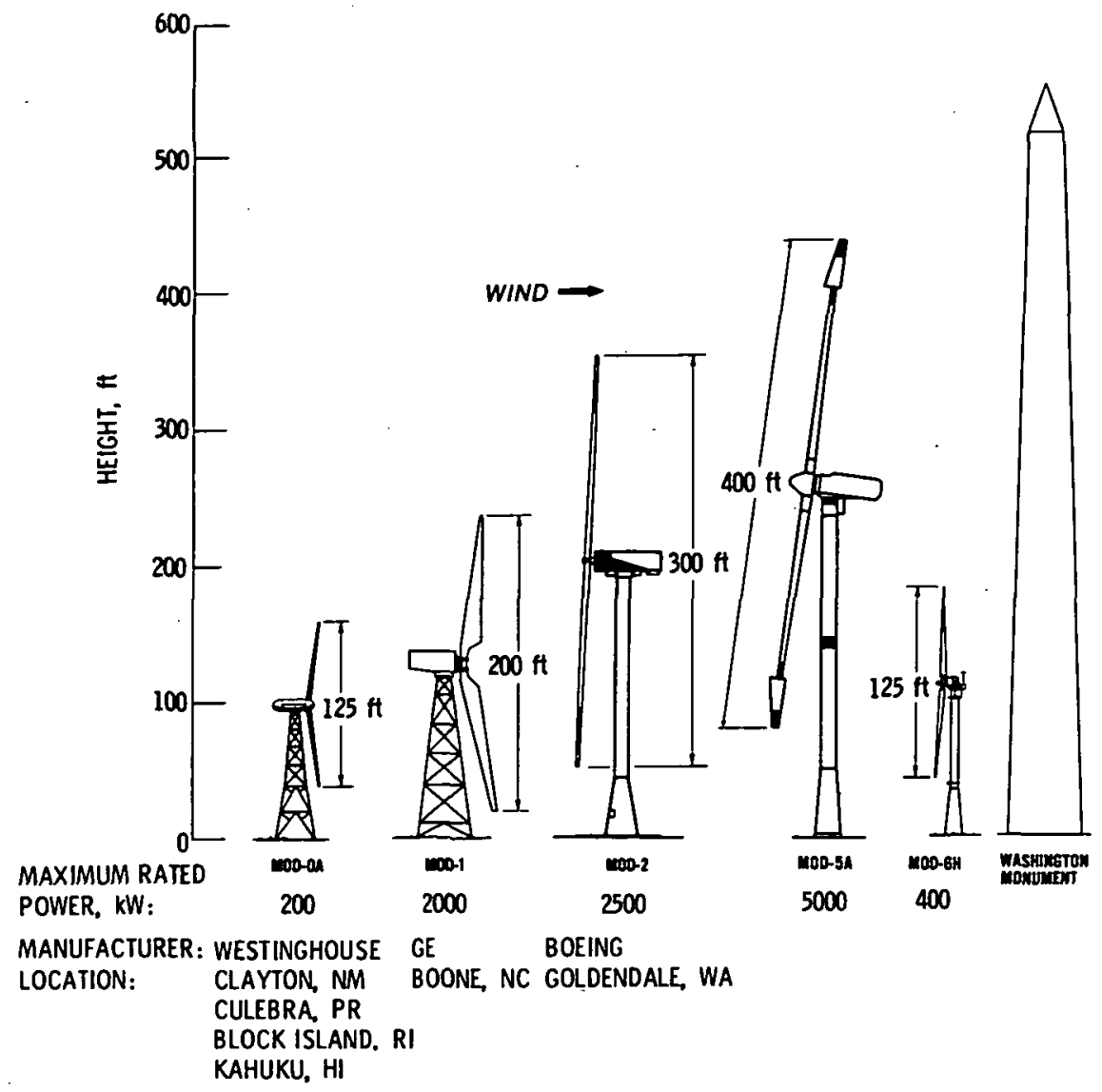

Figure 3. - Large horizontal-axis wind turbines.

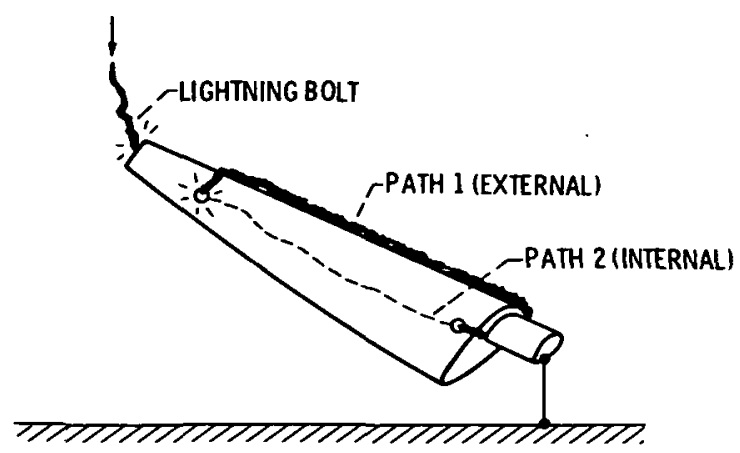

Figure 4. - External charge transfer and internal streamering.
AVERAGE oV/dt .

$1000 \mathrm{KV} / \mu \mathrm{LS} \pm 50$ percent 7

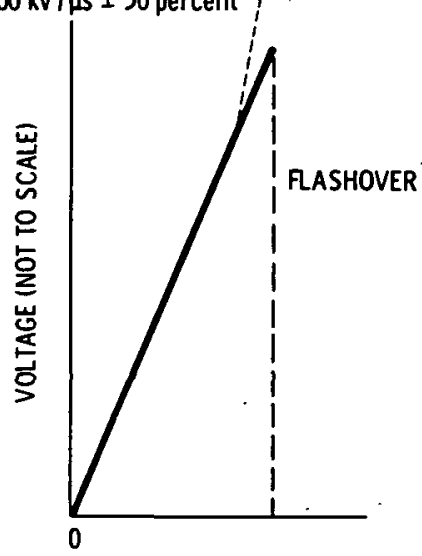

Figure 5. - Waveform A. (From ref. 6.) 


\section{CRIGINAL PAGE \\ BLACK AND WHITE PHOTOGRAPH}

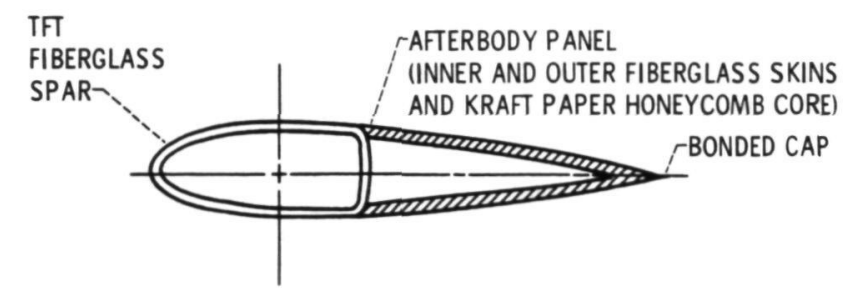

Figure 6. - Kaman test specimen.

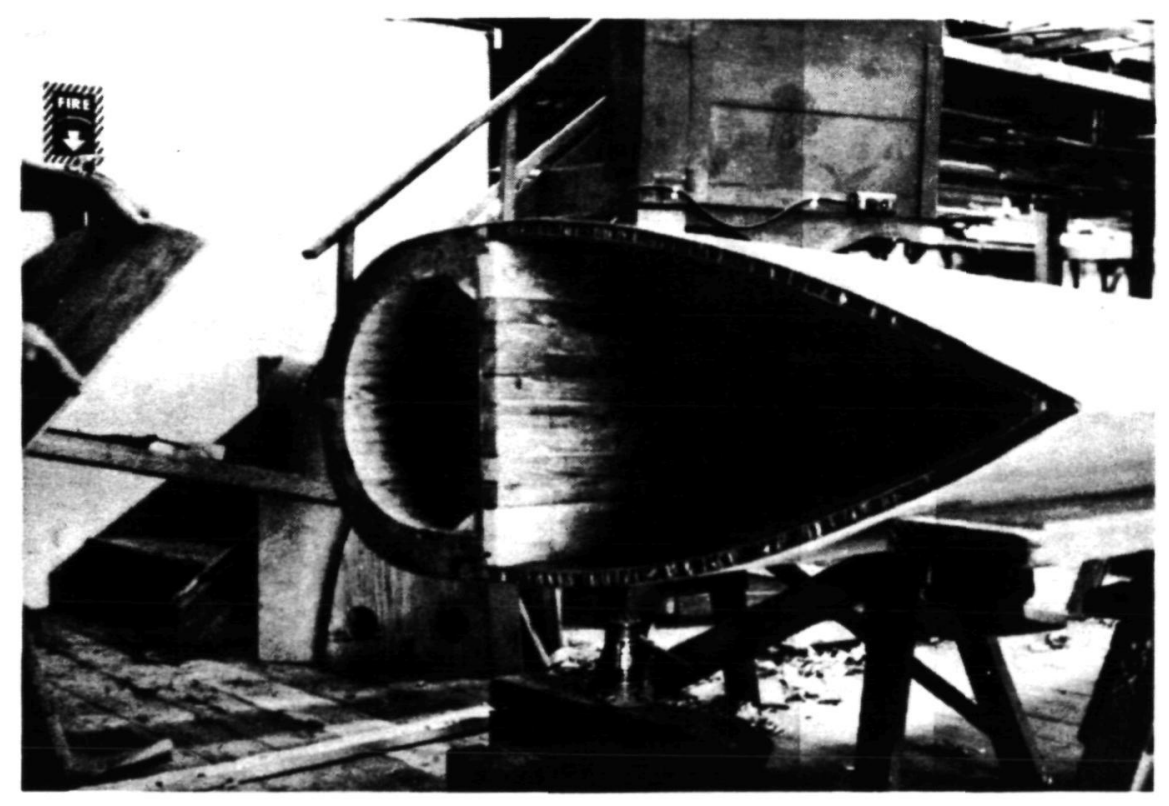

Figure 7. - Cross section of Gougeon Bros. test specimen. 


\section{ORGWA FAG \\ BLACK AND WHITE PHCTOGRAFH}
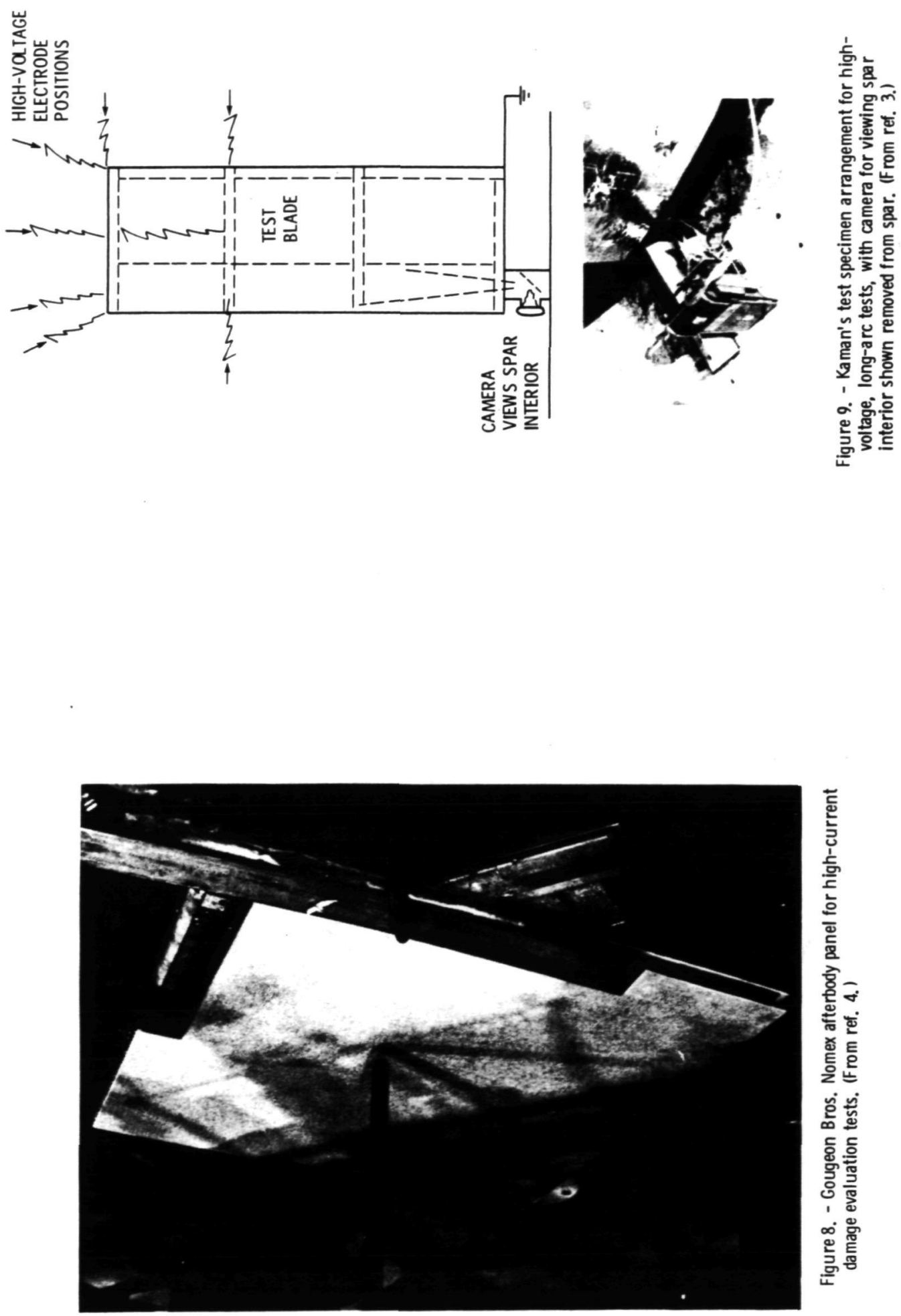
BLACK AND WHITE PHOTOGRAPH

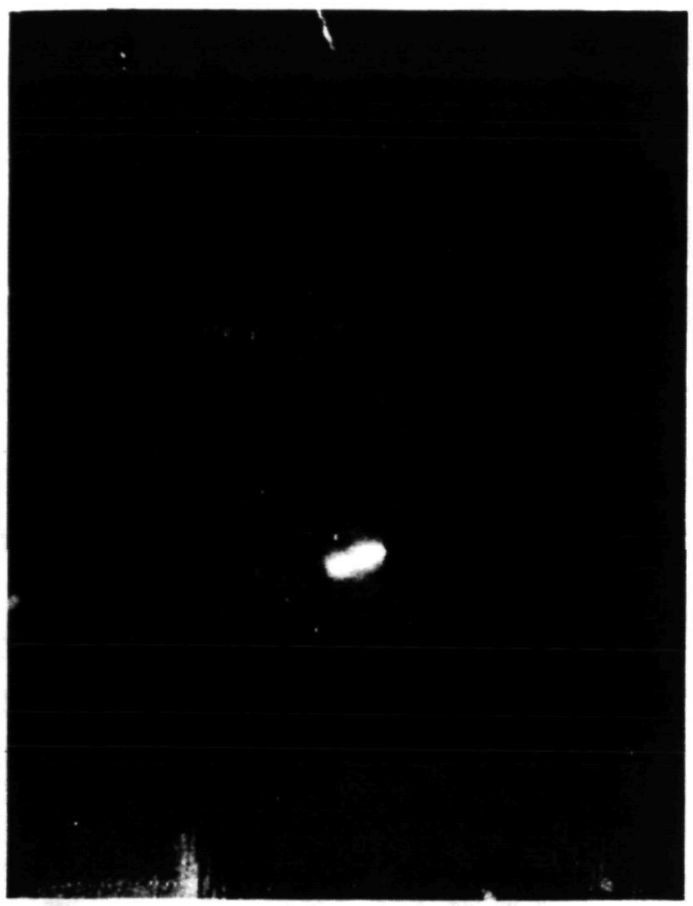

(a) Long-arc attachment on tip of Kaman test specimen.

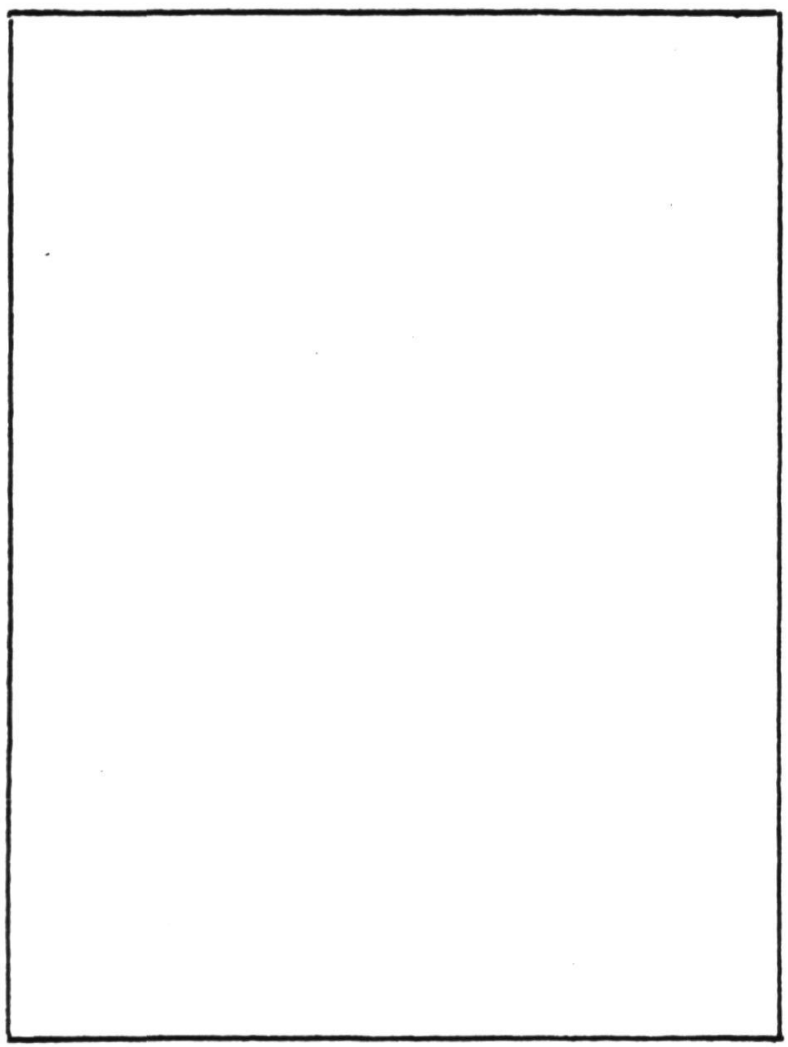

(b) Overexposure of interior camera due to streamering.

Figure 10. - Initial strikes showing penetration of tip and puncture to interior. (From ref. 3.) 


\section{or:ging- psez}

BLACK FNO WHITE PHOTOGRAPH

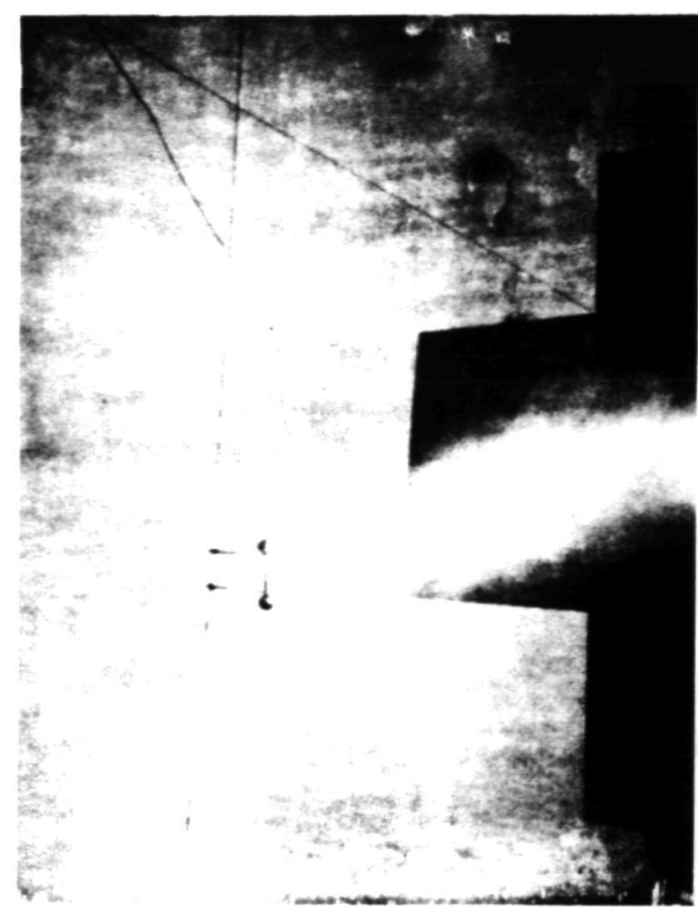

(a) Attachment at tip.

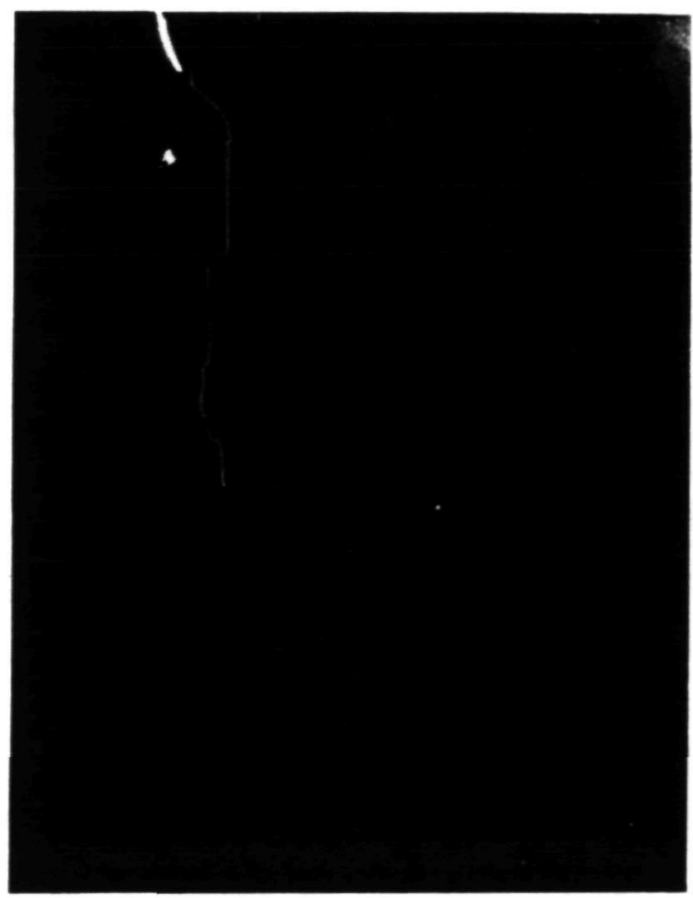

(c) Attachment at tip with external surface flashover.

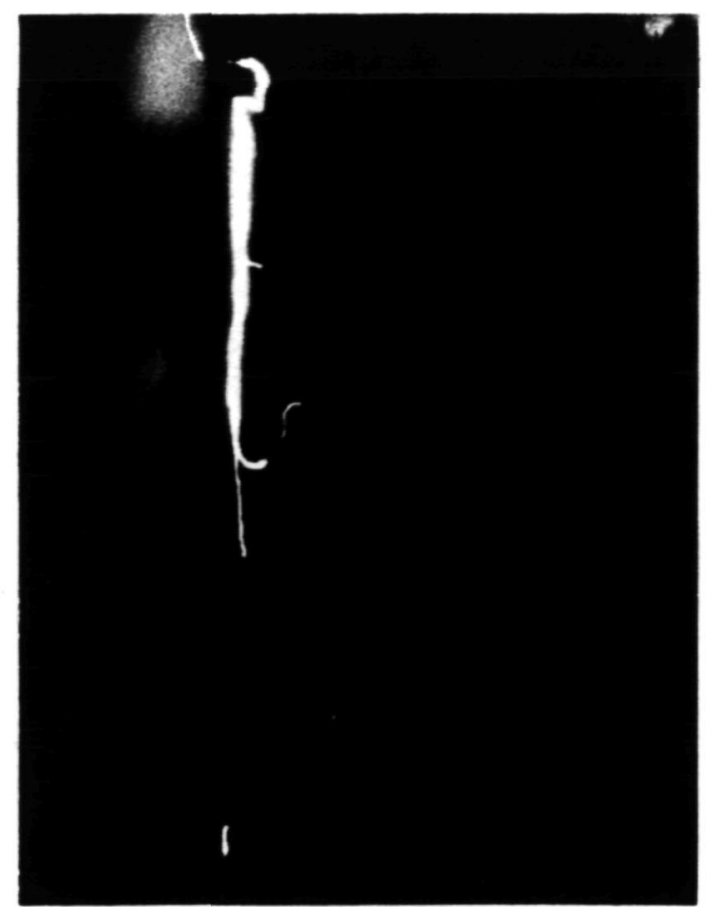

(b) Attachment at tip cap with external surface flashover and some stitching.

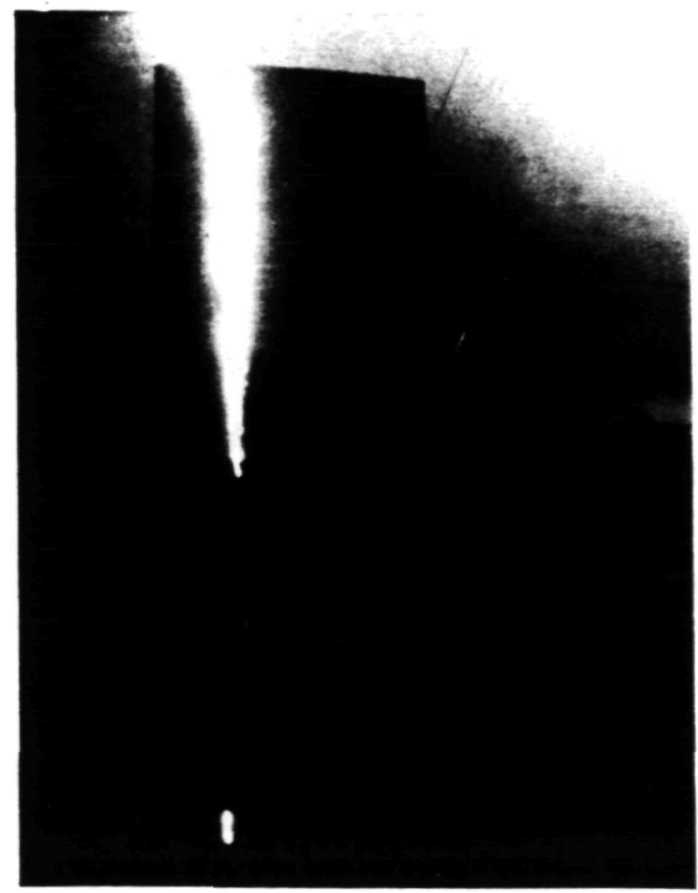

(d) Attachment at tip with external surface flashover followed by stitching and resurfacing.

Figure 11. - Long-arc attachment test series on Kaman specimen, (From ref. 3.). 


\section{ORIGNA: PAGE}

\section{BLACK AIND WHITE PHOTOGRAPH}

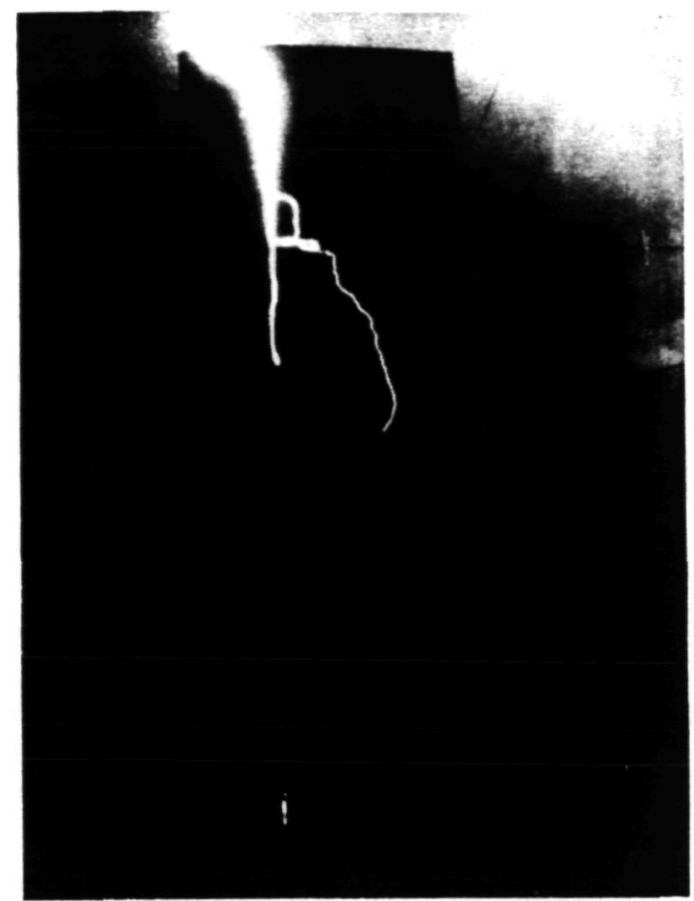

(e) Attachment at tip with external surface flashover and internal stitching (streamering).

Figure 11. - Concluded.

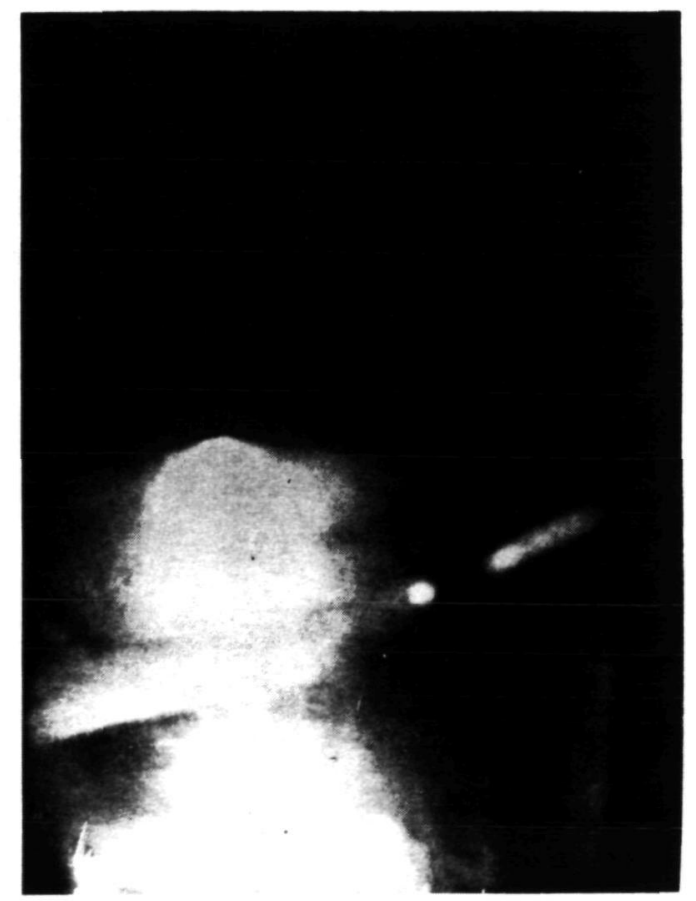

Figure 12. - Internal camera record of streamering in Kaman specimen. (From ref. 3.) 


\section{and}

BLACE AND WUIE PHOTOGRAPH
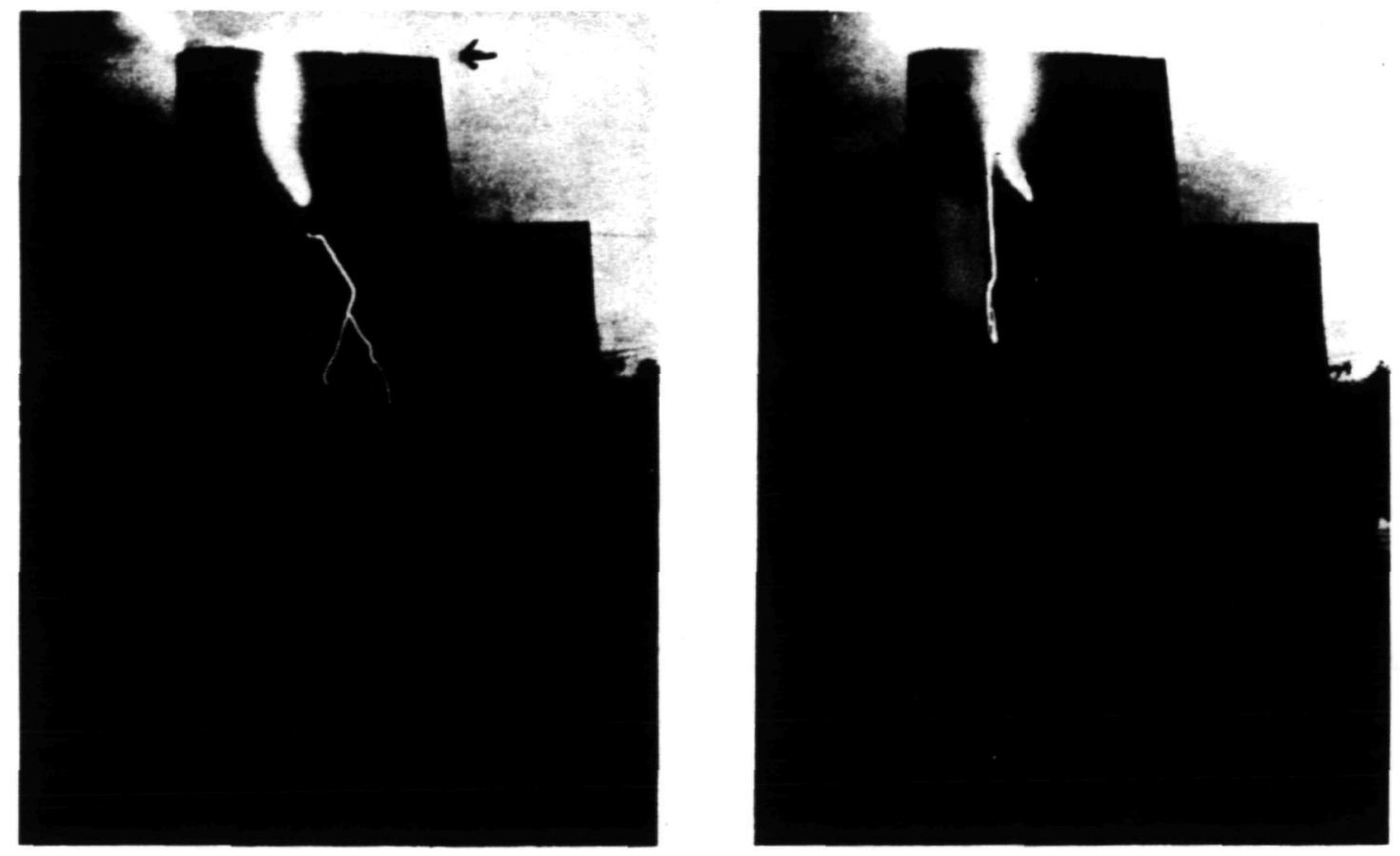

(a) Attachment on cap surface with flashover and some stitching.

Figure 13. - Long-arc attachment test series on Kaman specimen with metal tip cap. (From ref. 3.) 

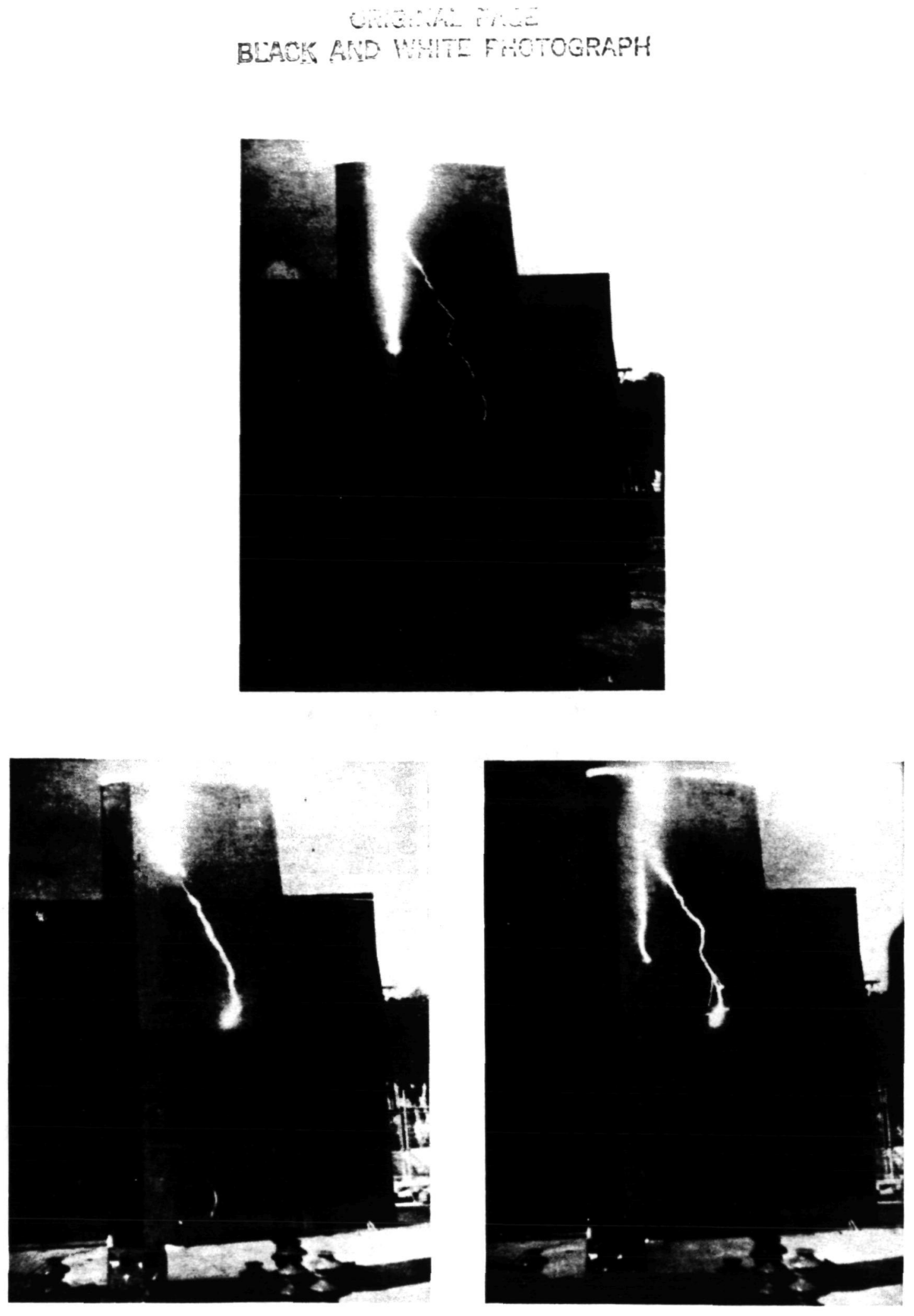

(b) Attachment on cap surface with external flashovers to metal base.

Figure 13. - Concluded. 


\section{ORIGINAL PAGE \\ BLACK AND WHITE PHOTOGRAPH}

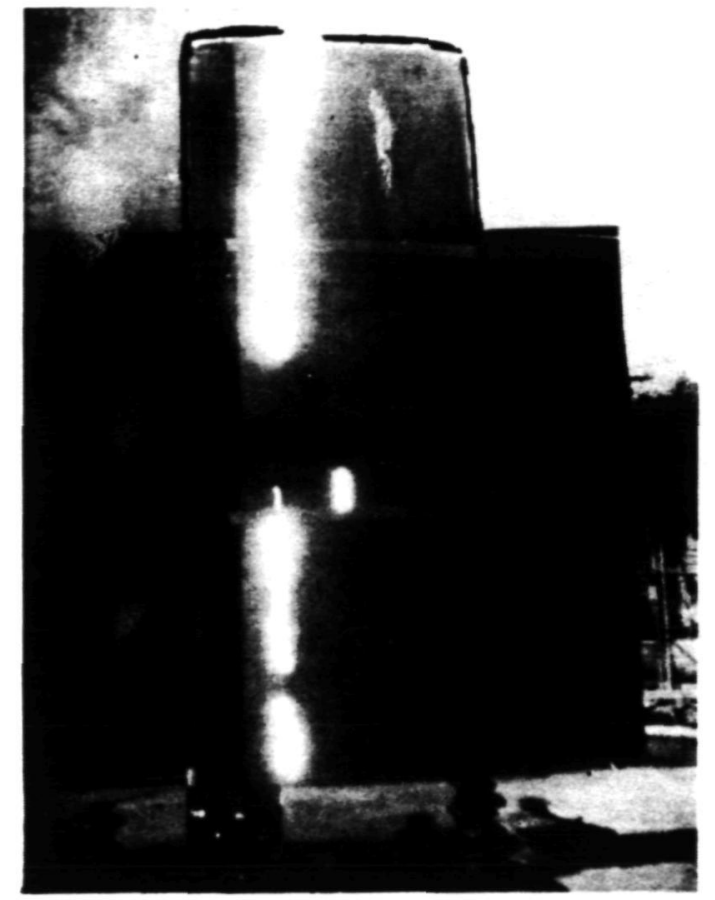

Figure 14. - Attachment at tip of Kaman specimen with external surface flashover and some stitching between chorowise strips. (From ref. 3.) 


\section{ORGINAL EAE \\ BLACK AND WHTE PHOTOGRAPH}
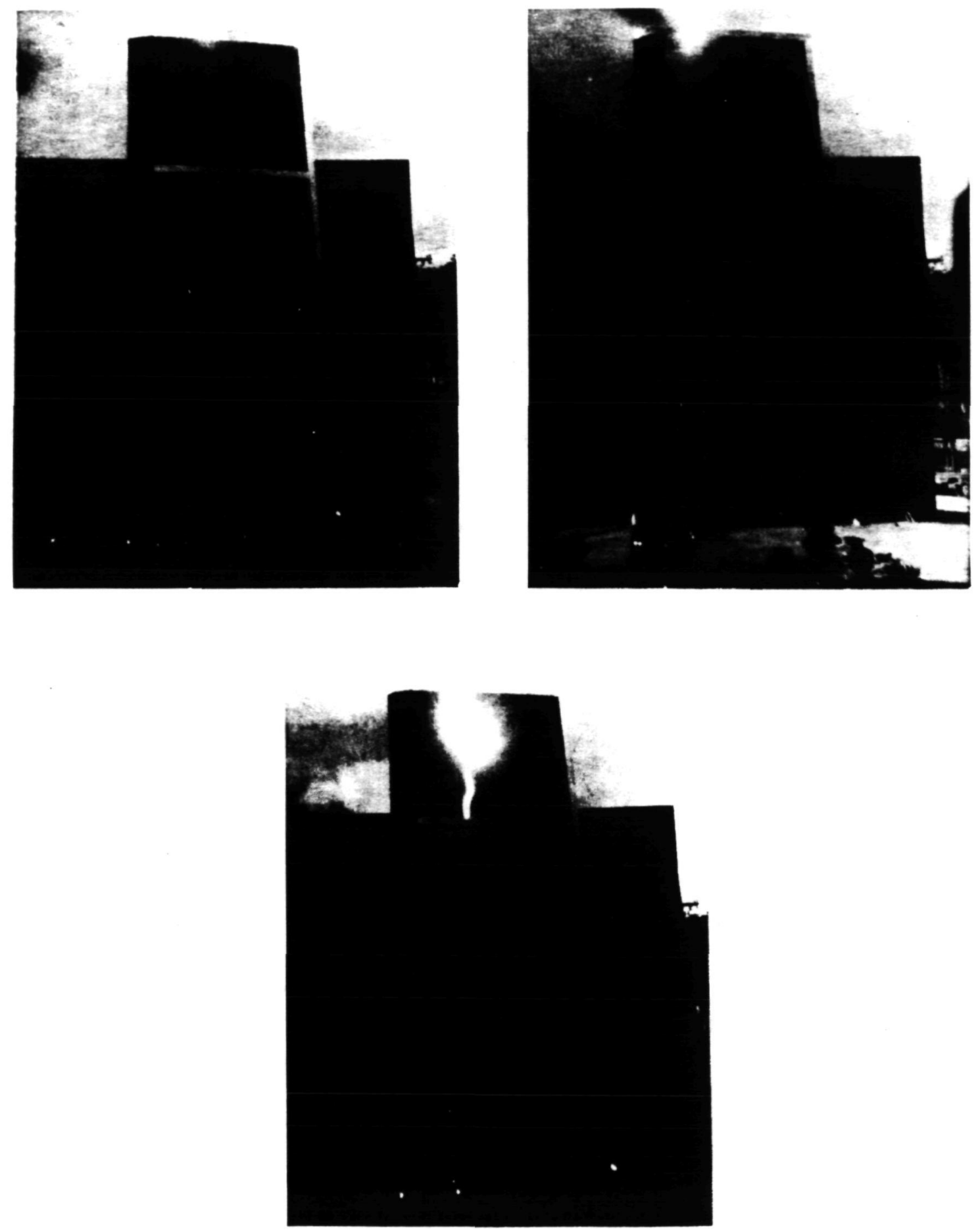

Figure 15. - Attachment at or near tip with external surface flashover and no stitching. (F rom ref. 3.) 


\section{CRGINAL PAGE \\ BLACK AND WHITE PHOTOGRAPH}

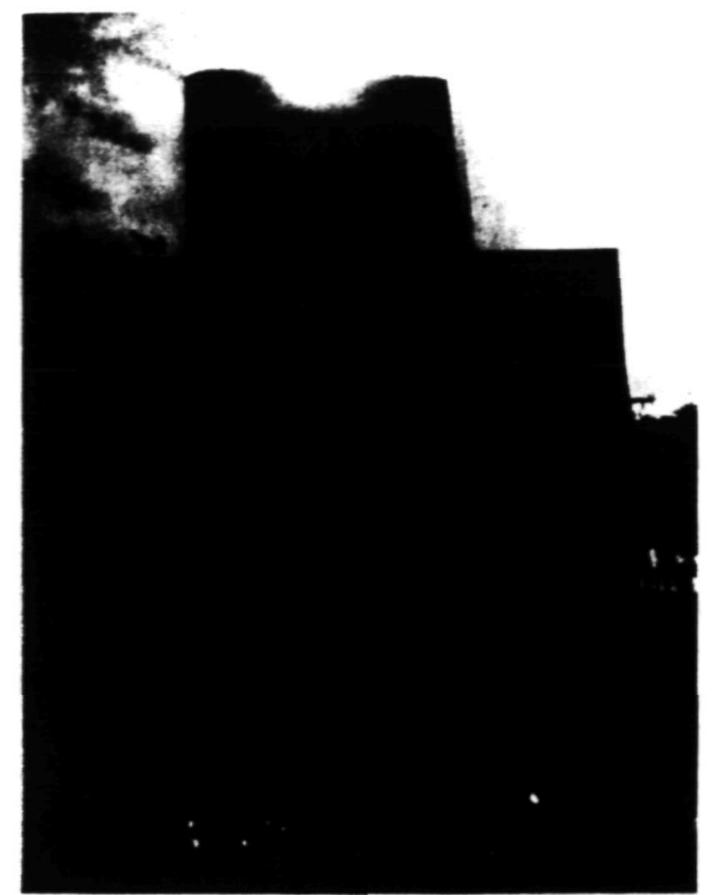

(a) Attachment at tip cap with midstrip removed.

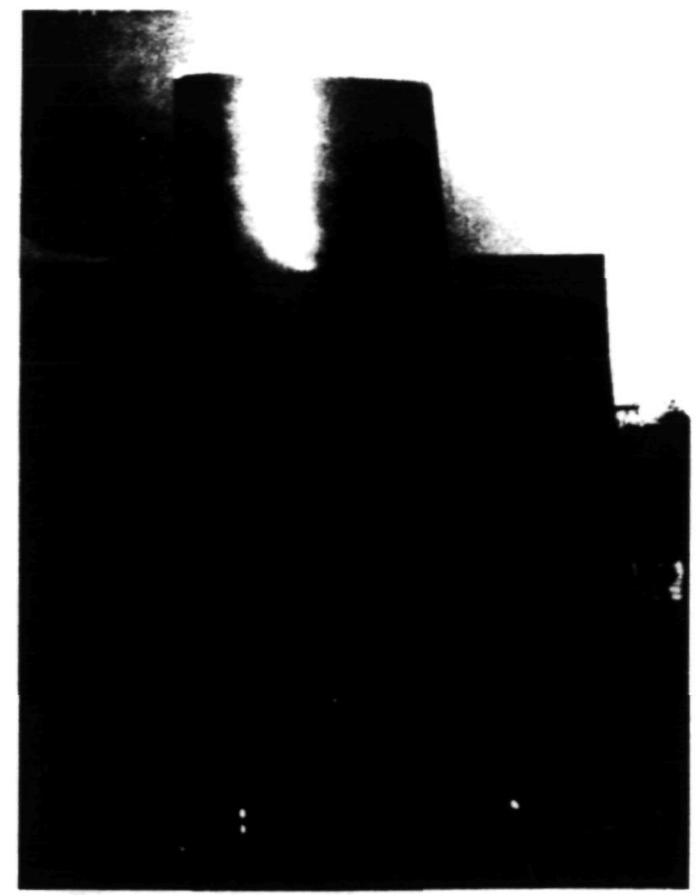

(b) Attachment at tip with external surface flashover and stitching.

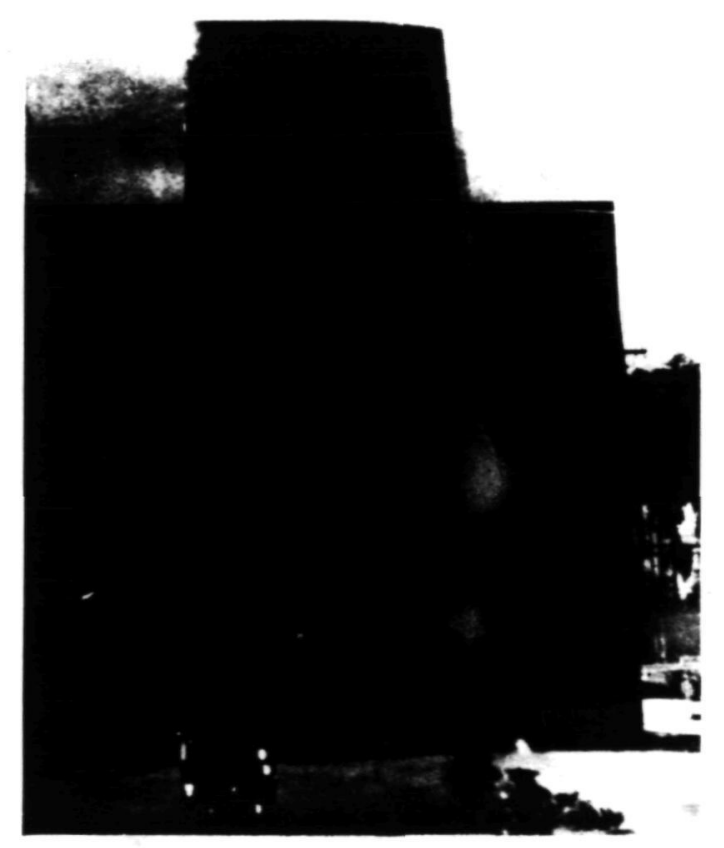

(c) Attachment at leading edge.

Figure 16. -.Progressive deletion of current paths on Kaman specimen. (From ref. 3.) 


\section{BLACK AND WINAL FAGE \\ AND WHITE PHOTOGRAPH}

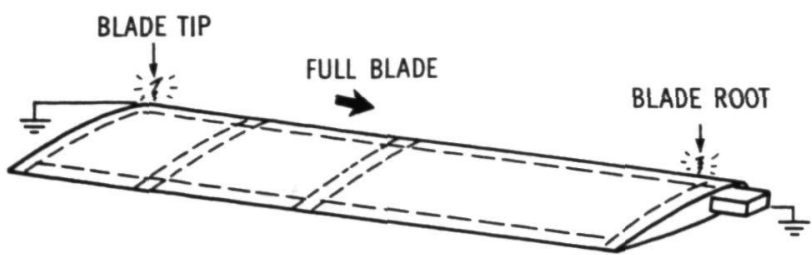

Figure 17. - Kaman test specimen arrangement for high-current damage tests. (From ref. 3.)

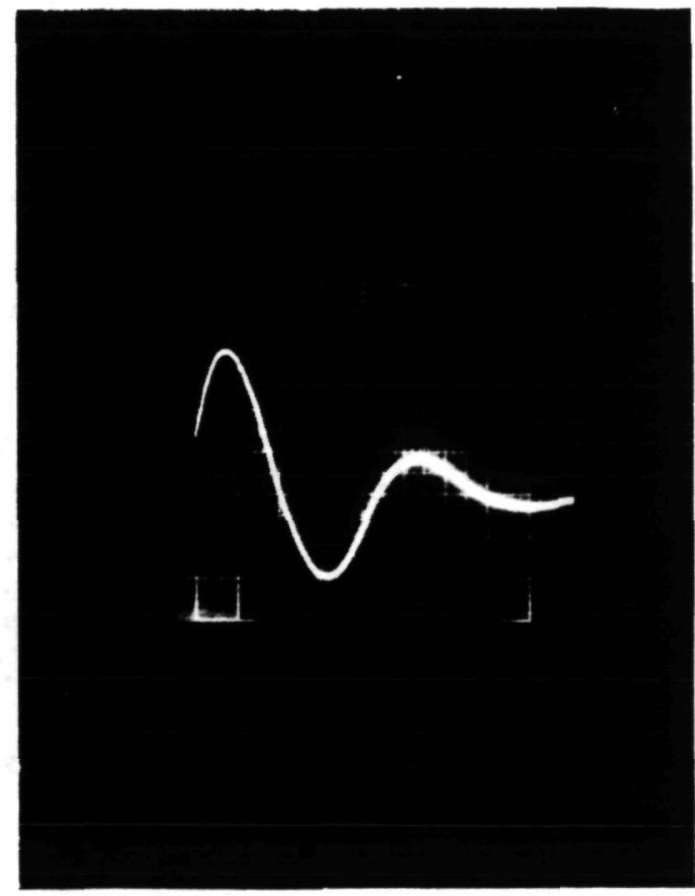

Figure 18. - High-current waveform oscillogram. (From ref. 3.) 


\section{ORIGINAL PAGE \\ BLACK AND WHITE PHOTOGRAPH}

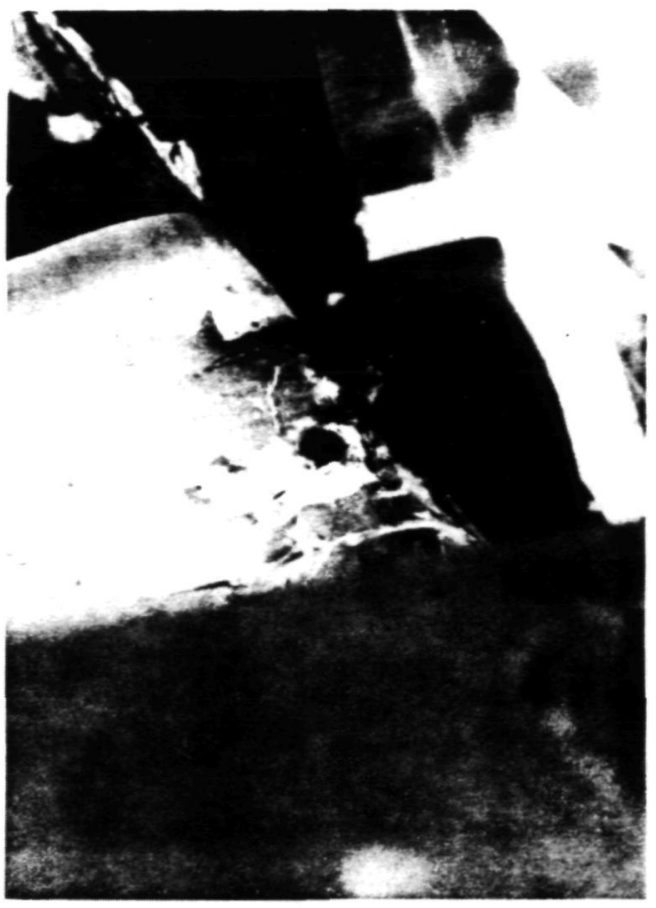

(a) Leading edge.

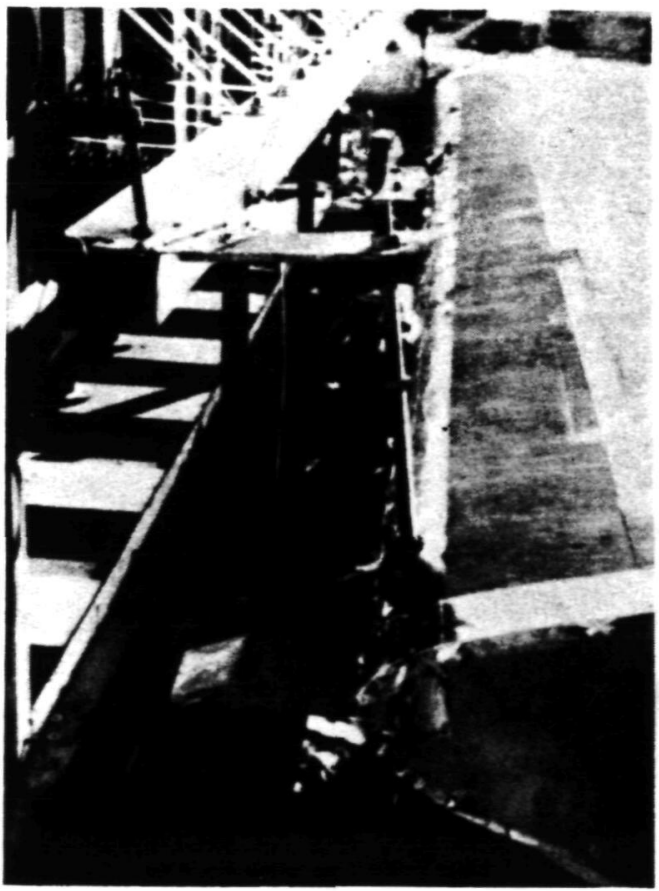

(c) Tip leading edge - full blade.

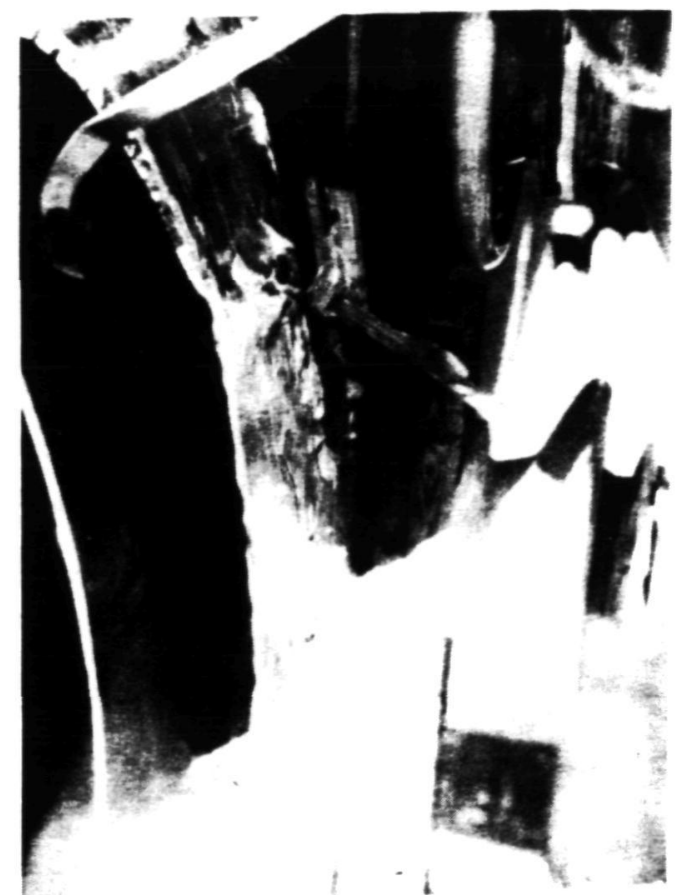

(b) Hub area.

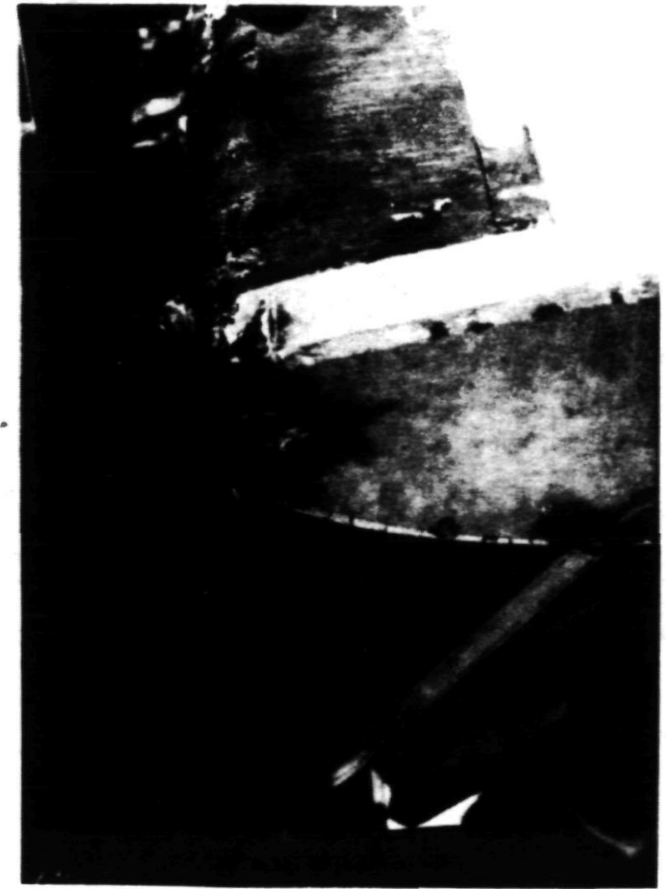

(d) Atop of leading edge.

Figure 19. - Foil damage as result of high-current tests. (From ref. 3.) 

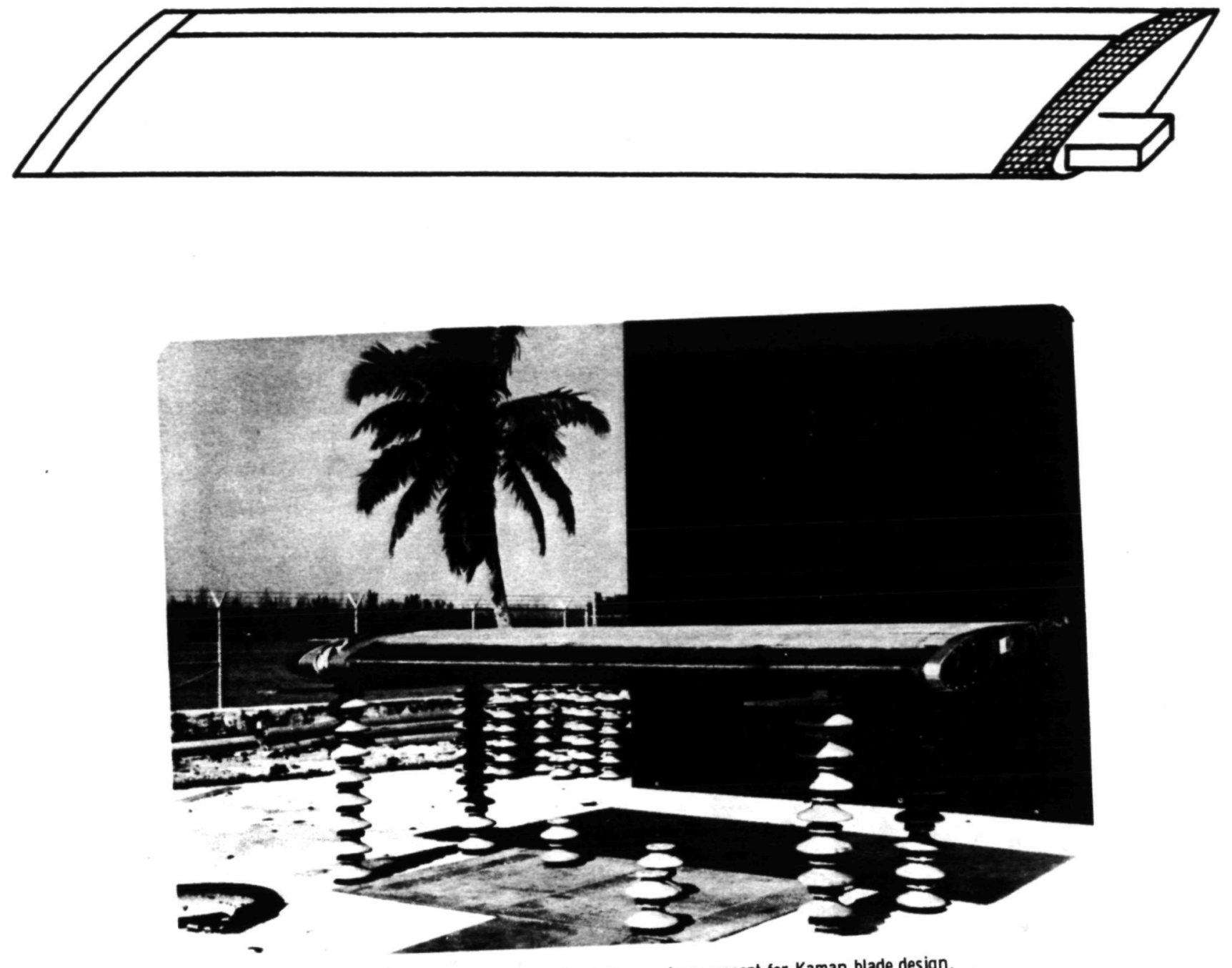

Figure 20. - Lightning accommodation system concept for Kaman blade design.

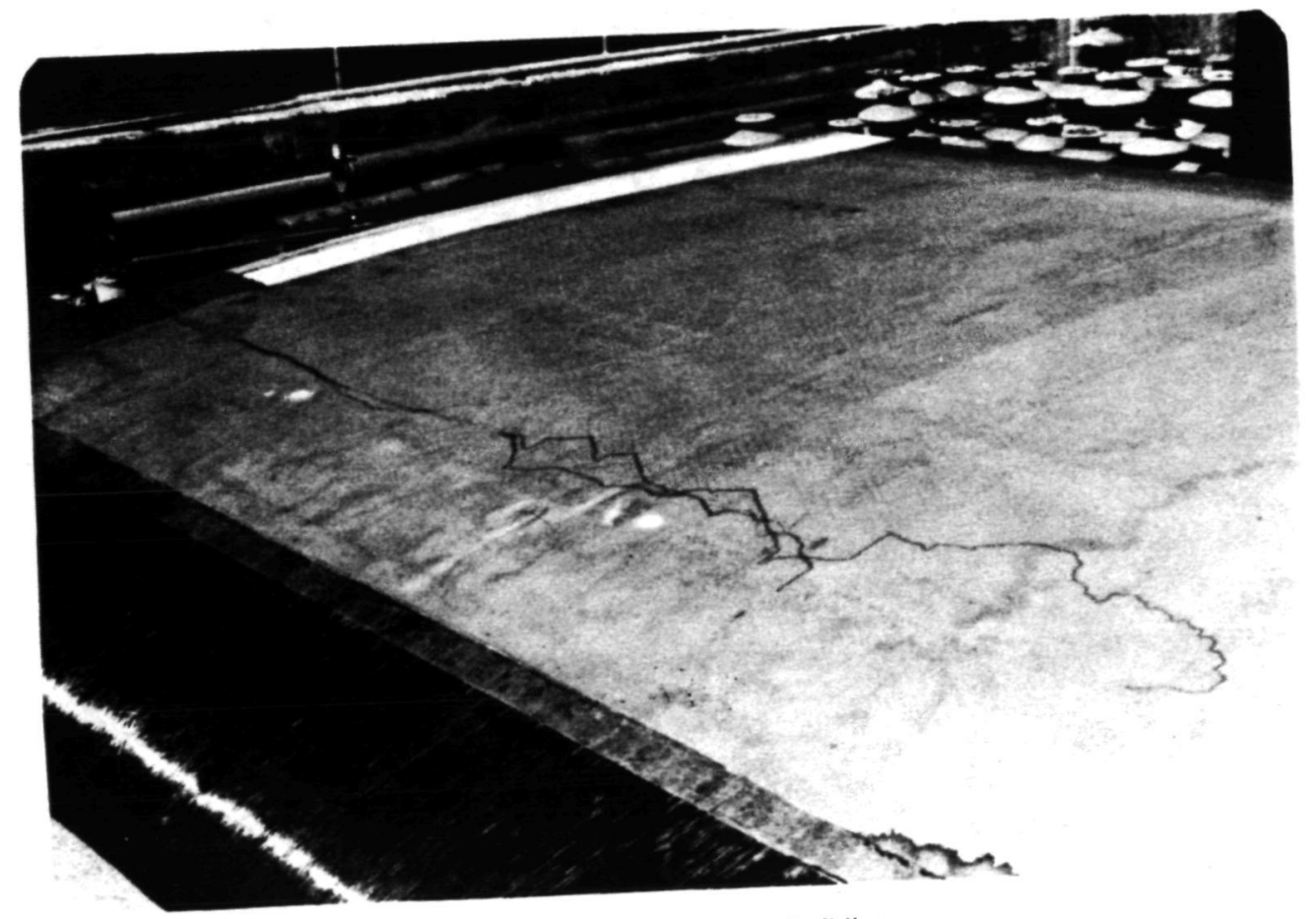

Figure 21. - Carbonaceous trail line. 


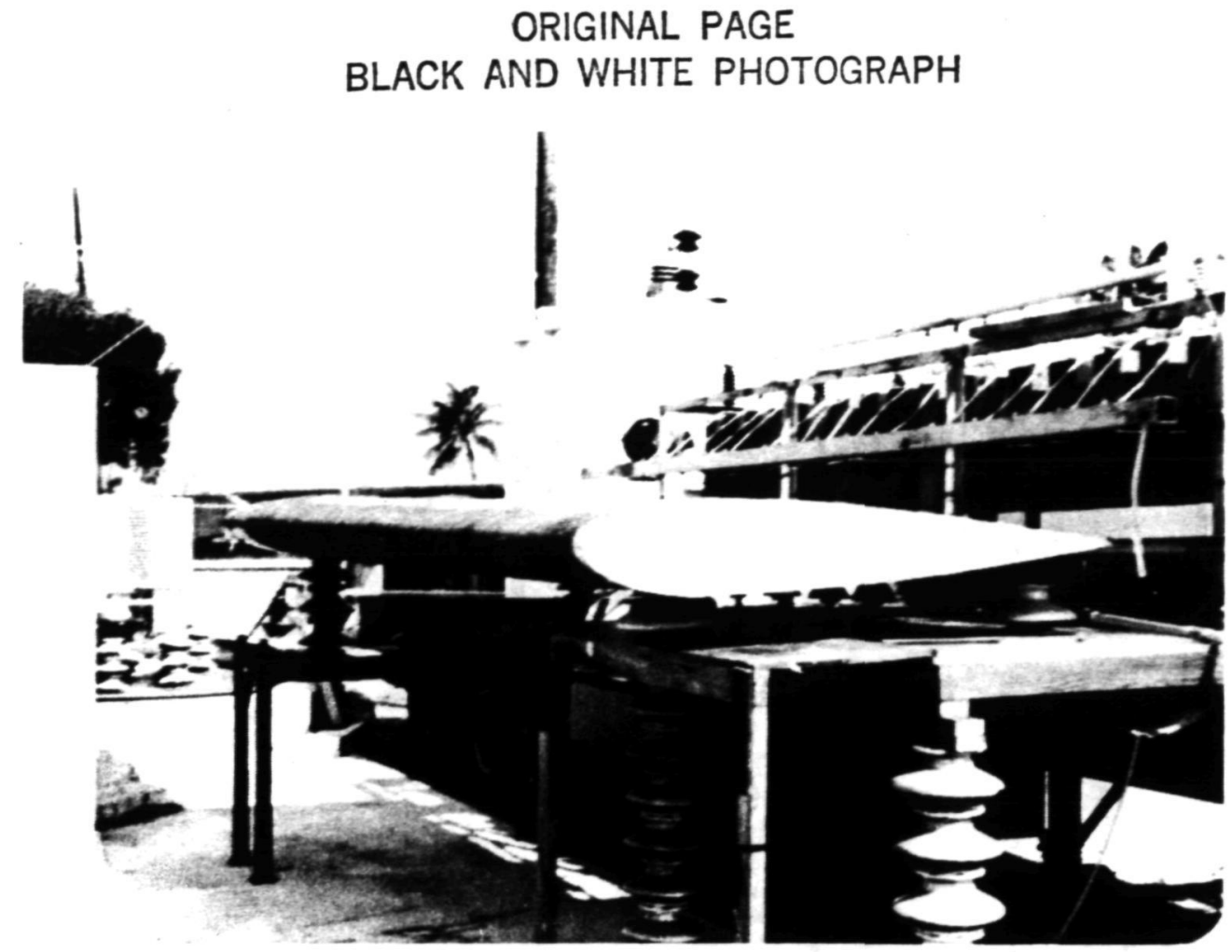

(a) Overall view.

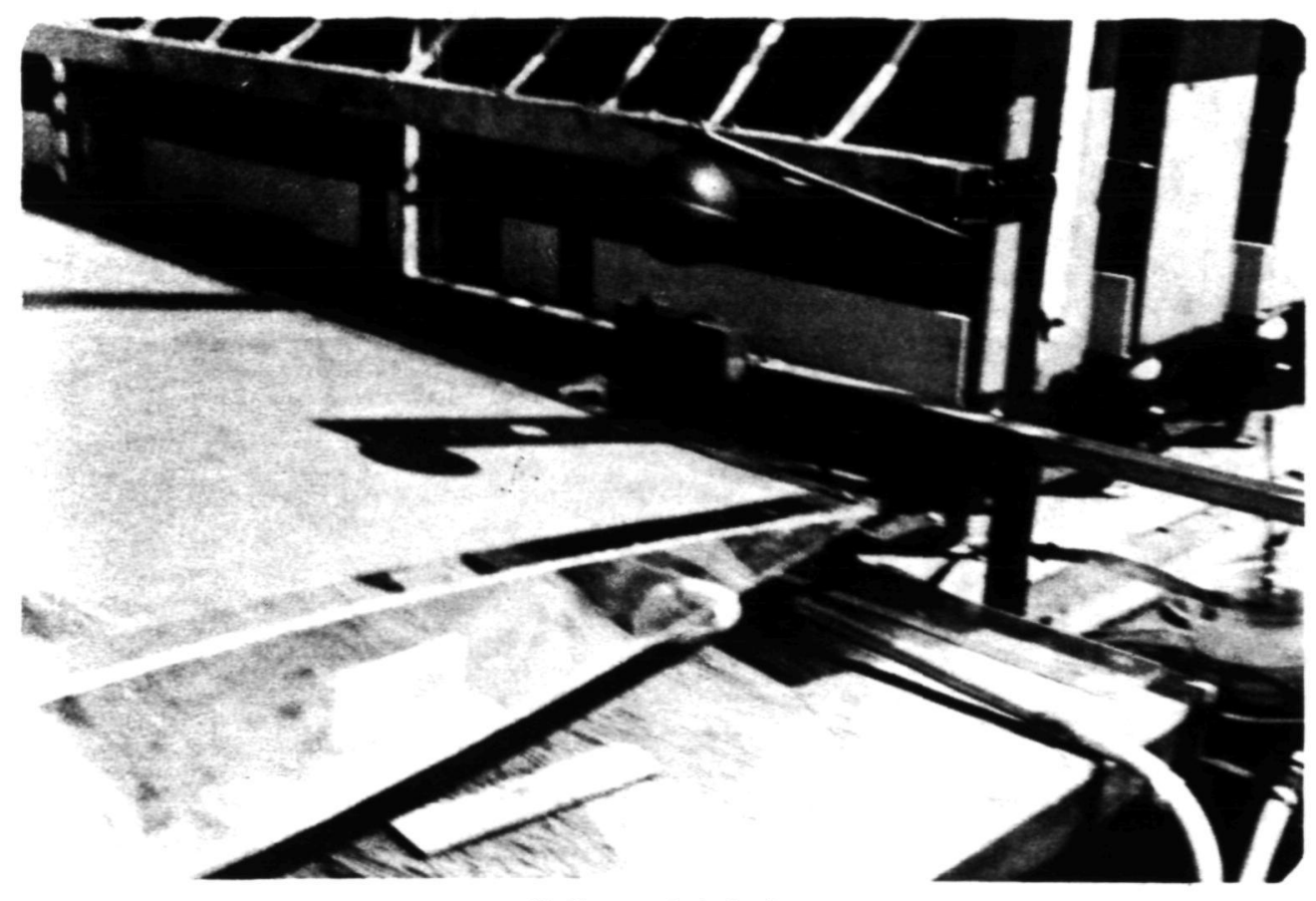

(b) Closeup of electrode.

Figure 22. - Kaman test specimen arrangement for second series of high-current damæae tests. 
BLACK AND WHITE PHOTOGRAPH

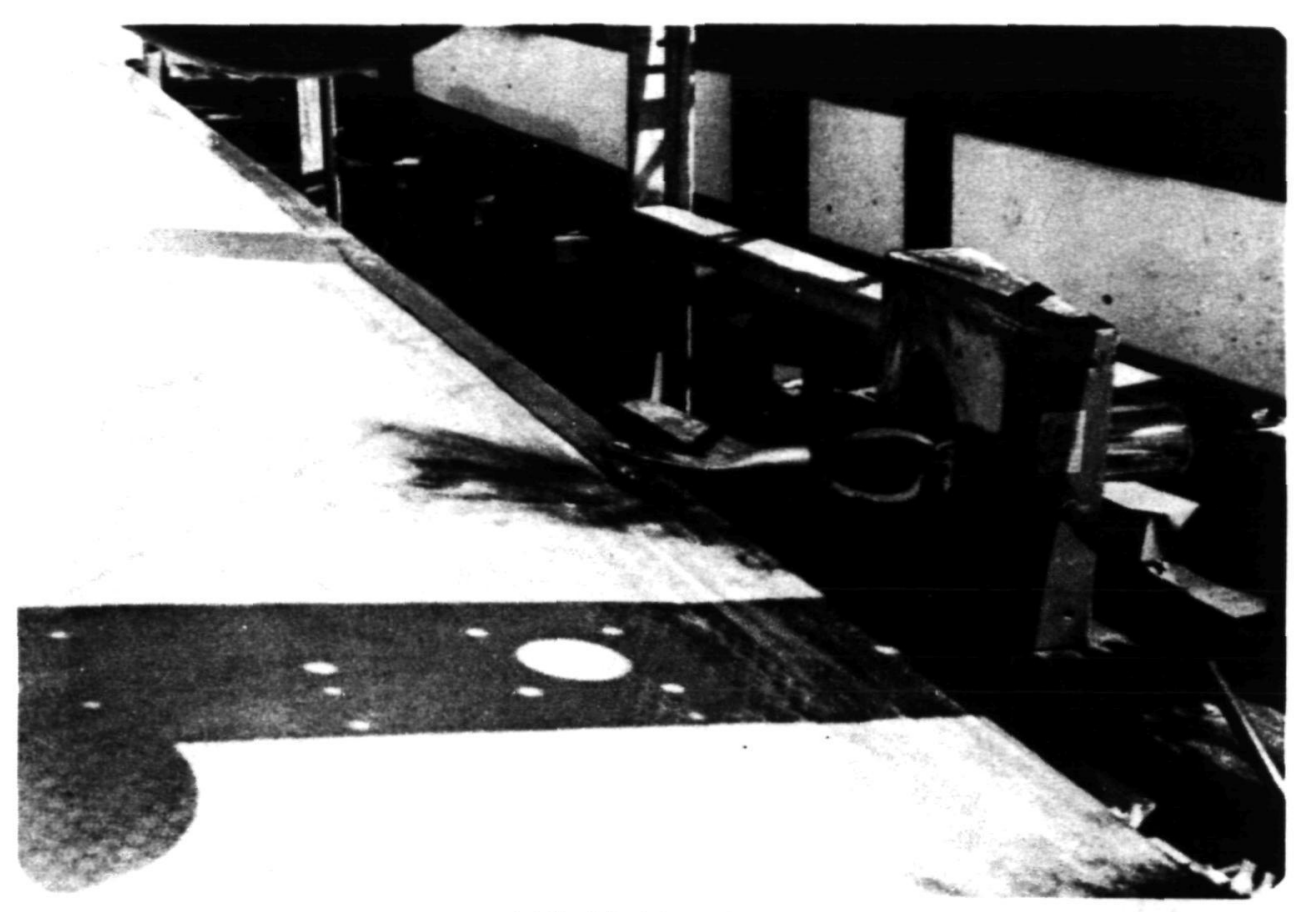

(a) Post-test damage.

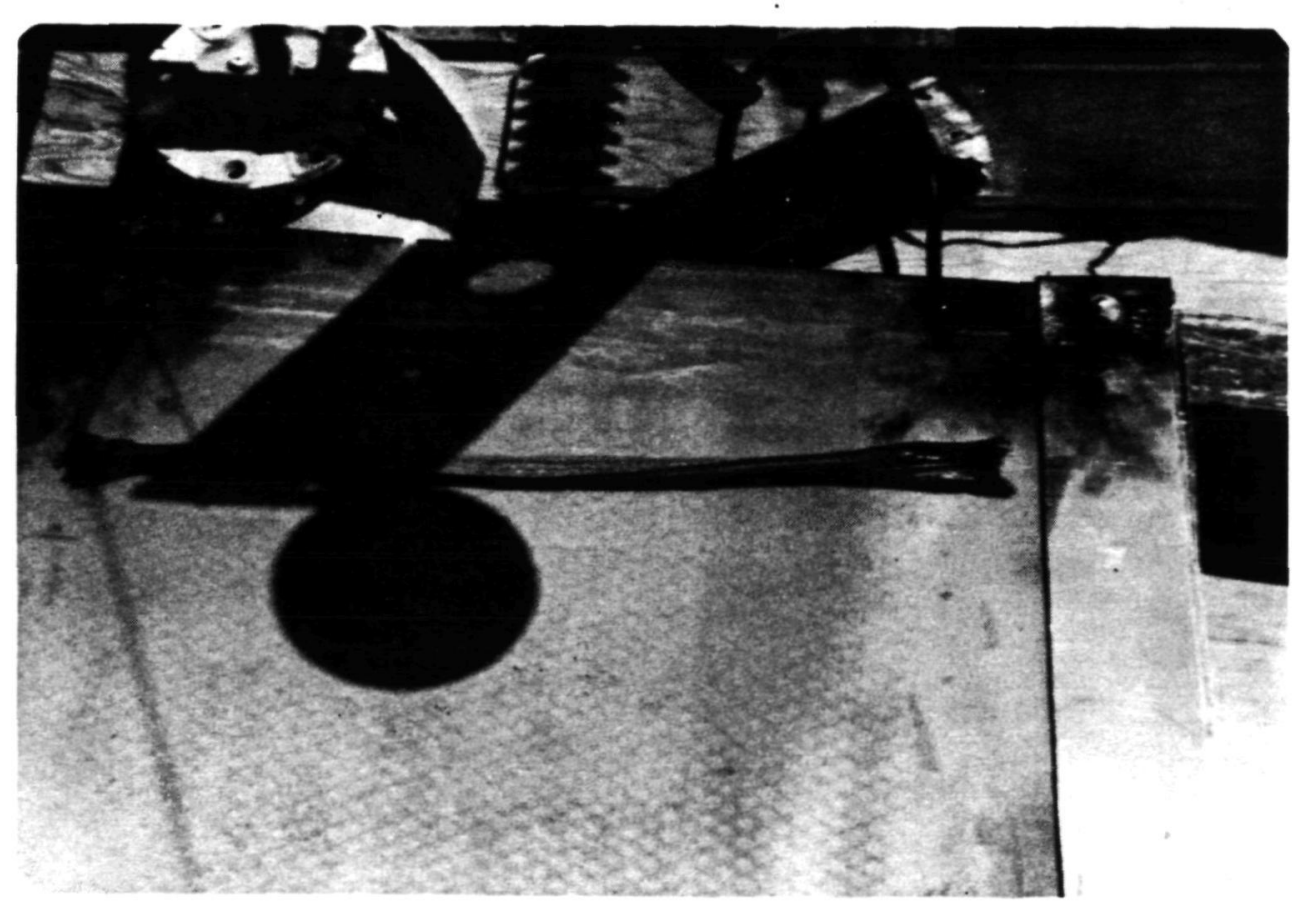

(b) Blown-off segment.

Figure 23. - Blown-off flat, braided-cable down-conductor. 


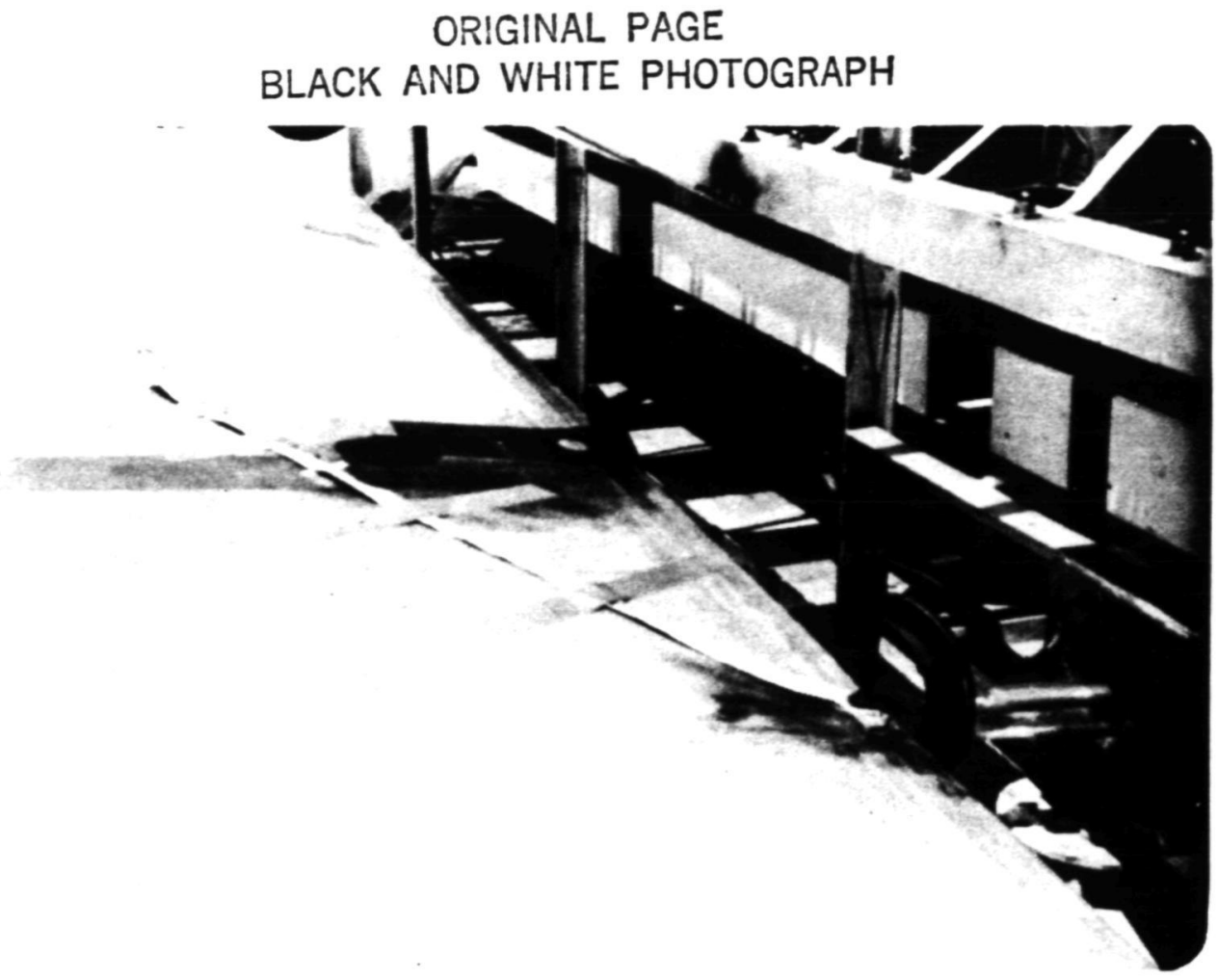

Figure 24. - Test arrangement for progressively higher current damage tests.

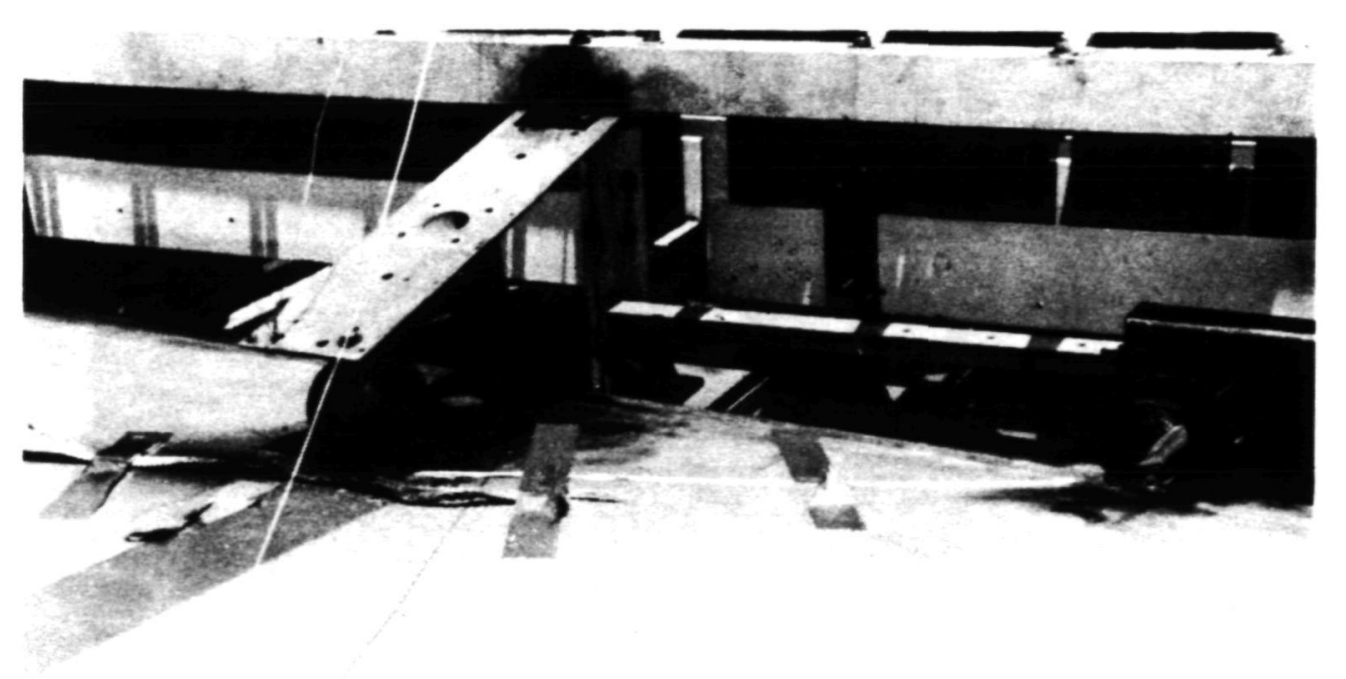

Figure 25. - Aftermath of 246-kA current passage through sample. 


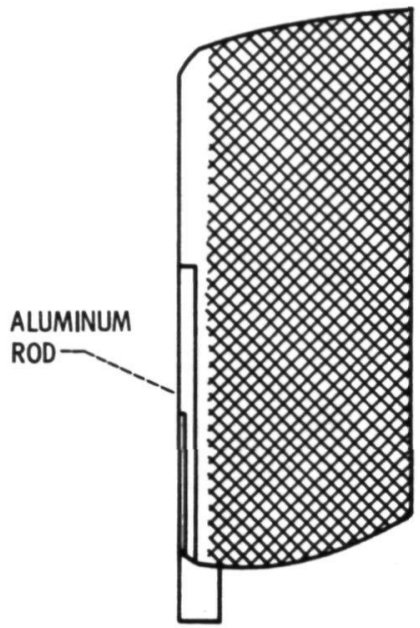

(a) Full surface coverage by aluminum screen.

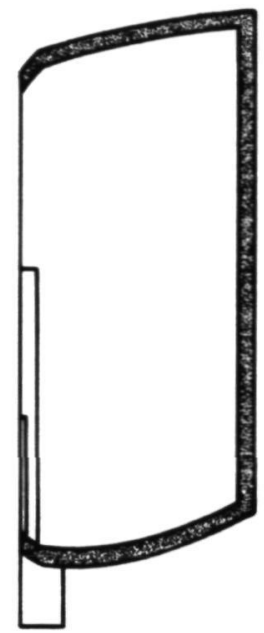

(b) Metal tip cap with trailing edge down conductor.

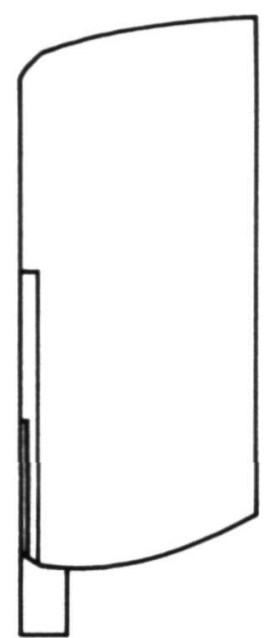

(c) No accommodations.

Figure 26. - Sketch of Gougeon Bros. test specimen.

5-MV MARX GENERATOR

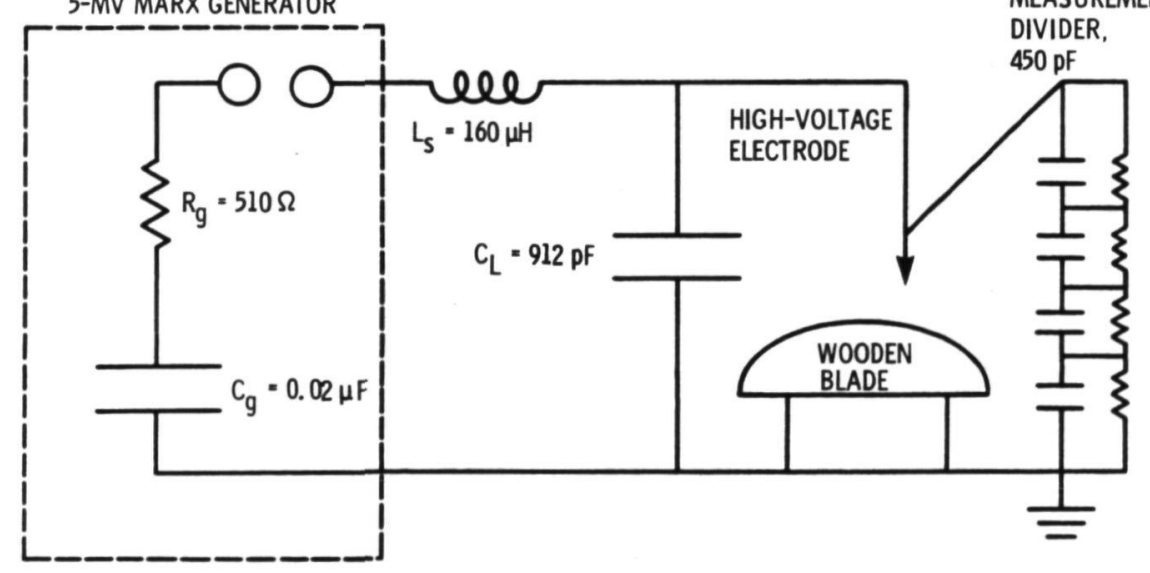

Figure 27. - Test circuit for simulated lightning strike attachment tests. (From ref. 4.) 


\section{OR!GINAL PA.GE \\ BLACK AND WHITE PHOTOGRAPH}

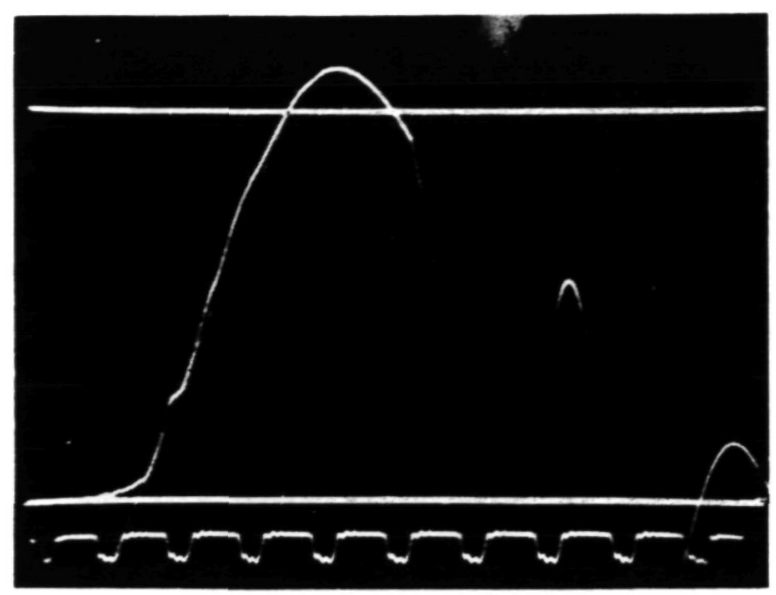

Figure 28. - Waveform calibration. (F rom ref. 4.)

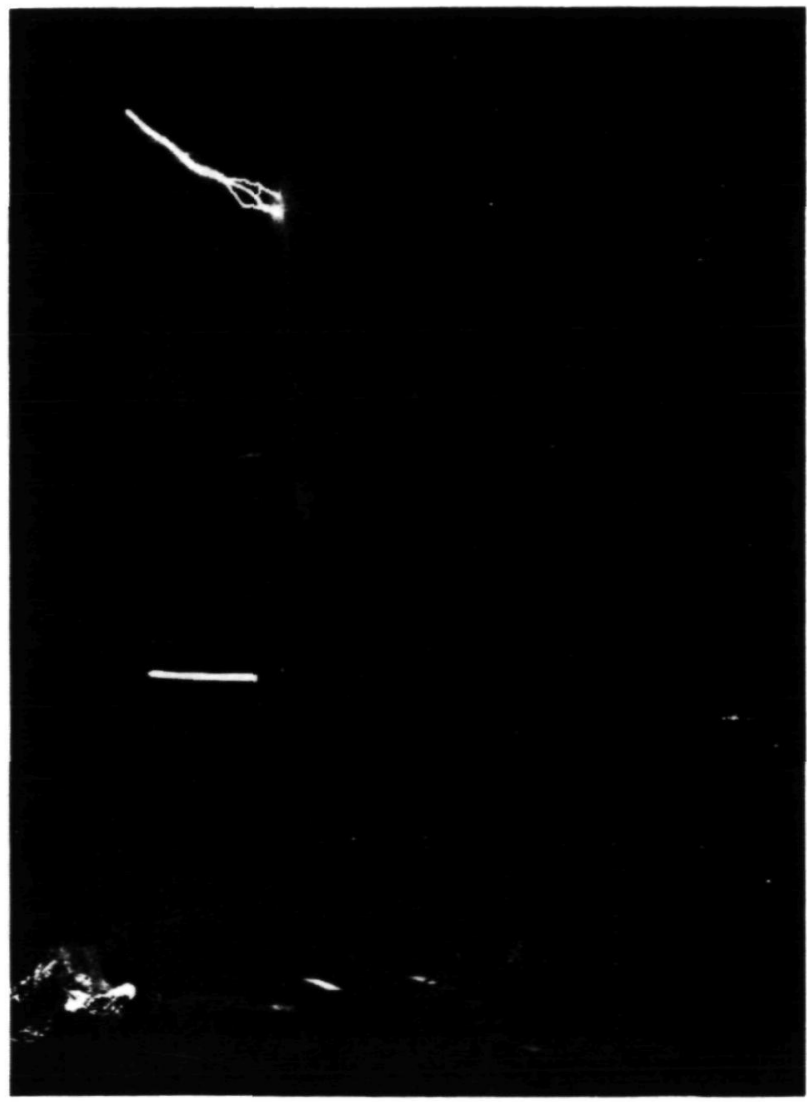

Figure 29. - Attempted attachment to leading edge lactually attaching to screen). (From ref. 4.) 


\section{ORIGINAL PAGE}

BLACK AND WHITE PHOTOGRAPH
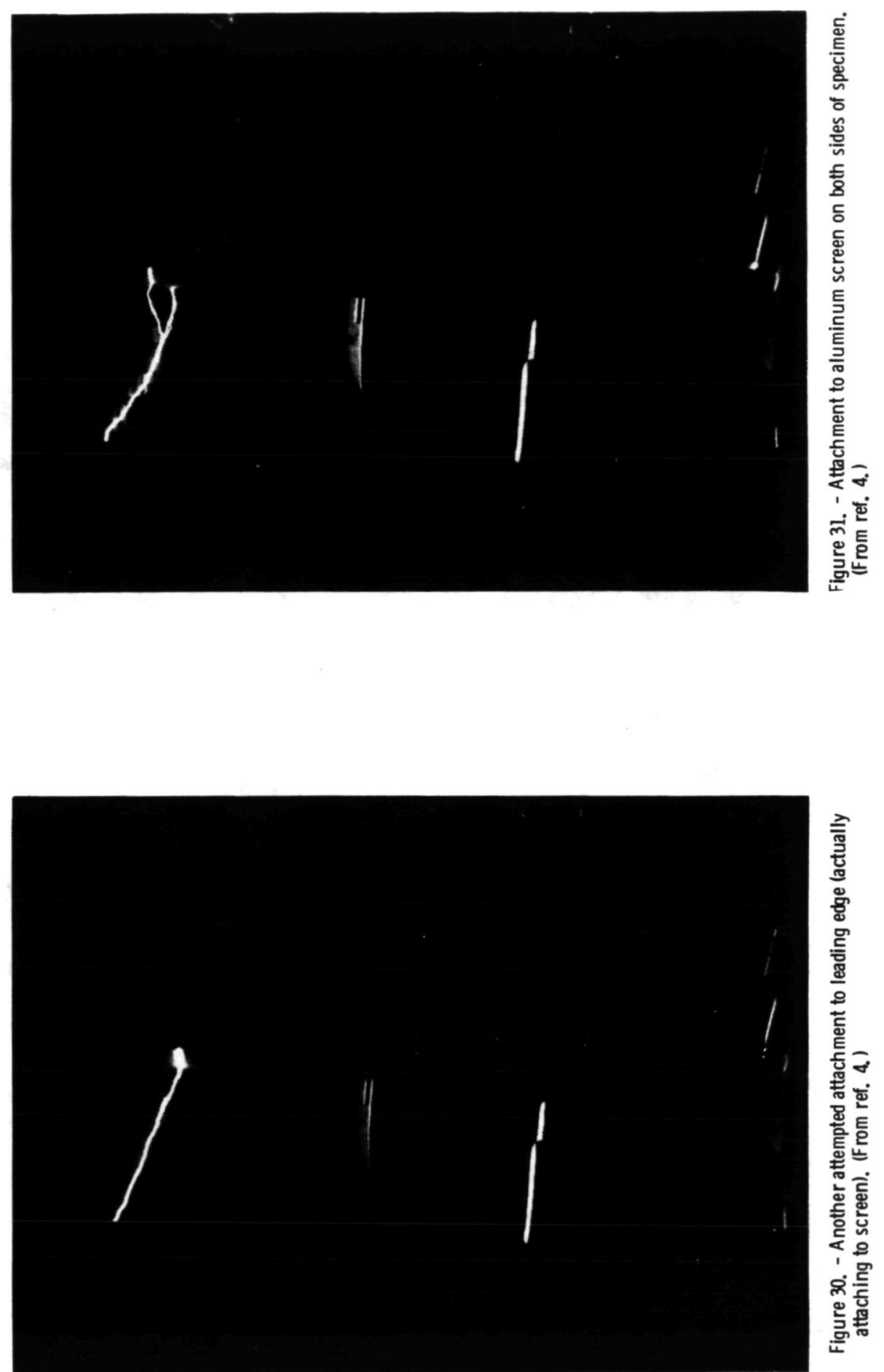
NOS PAOE

BLACK AND W'HITE PHOTOGRAPH

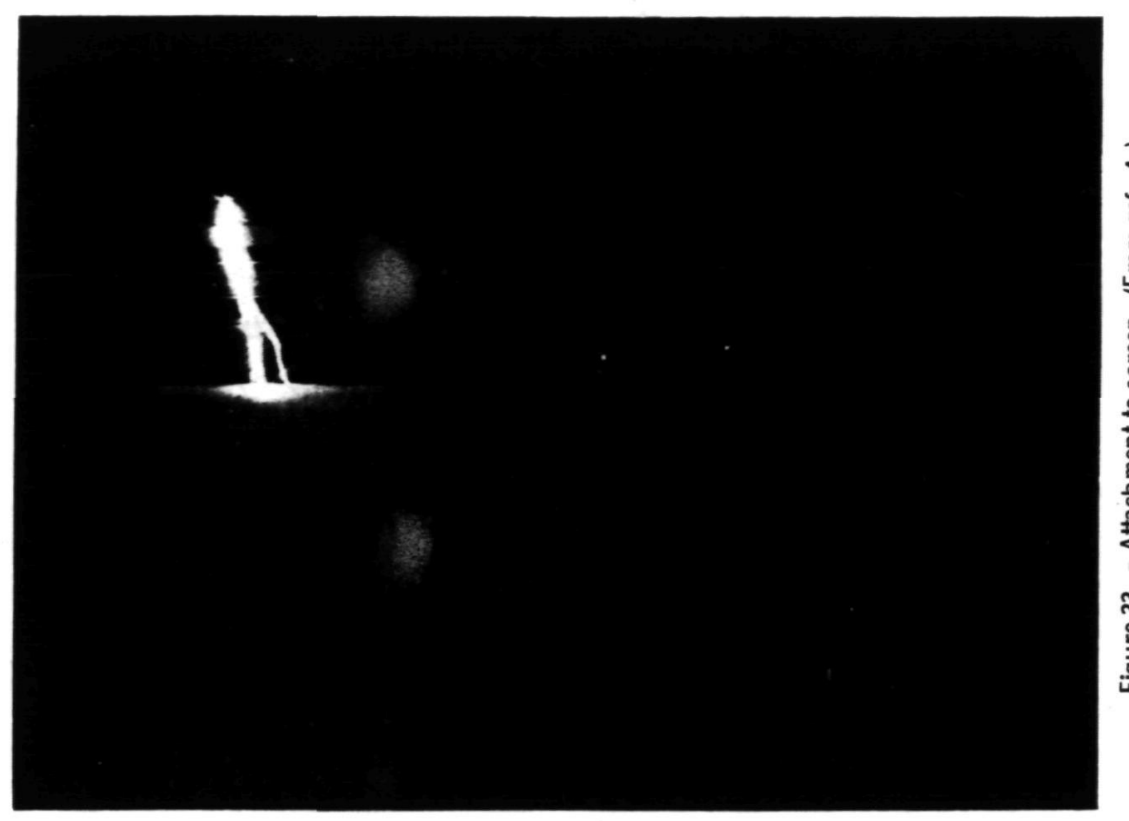

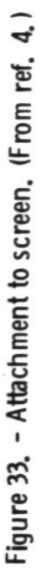
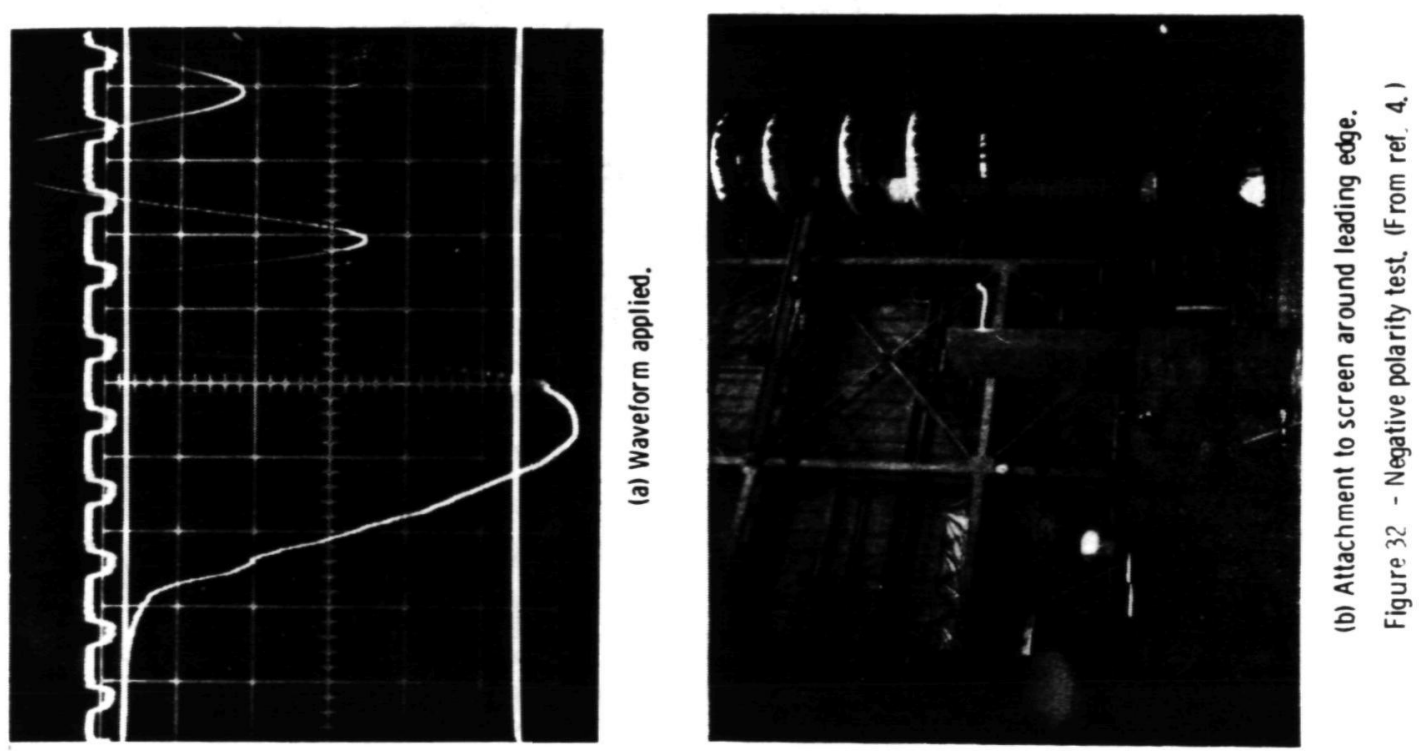


$$
\begin{gathered}
\text { CRIGINAL PAEE } \\
\text { BLACK AND WHITE PHOTOGRAPH }
\end{gathered}
$$
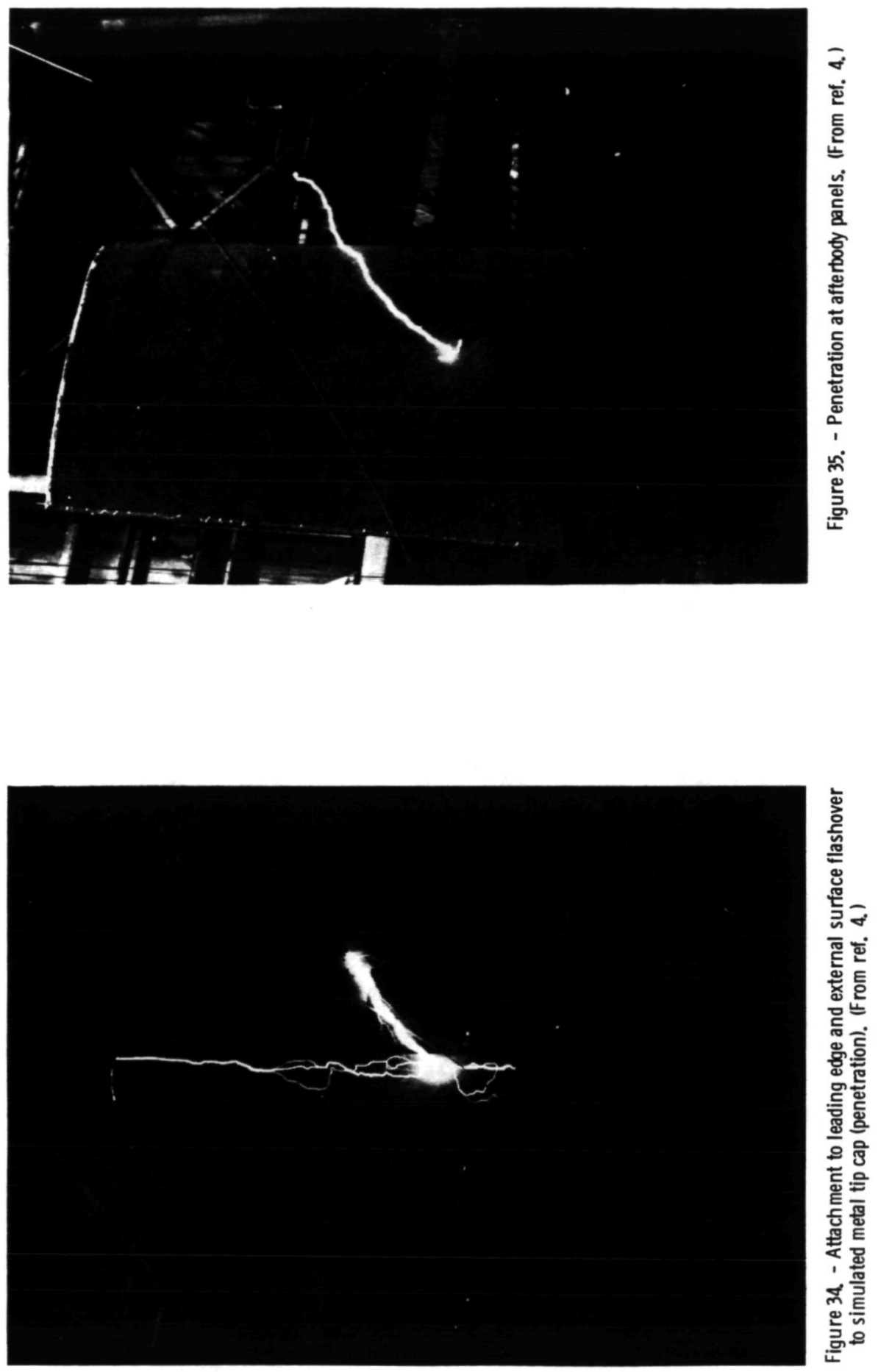


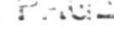

WHITE PHOTOGRAPH
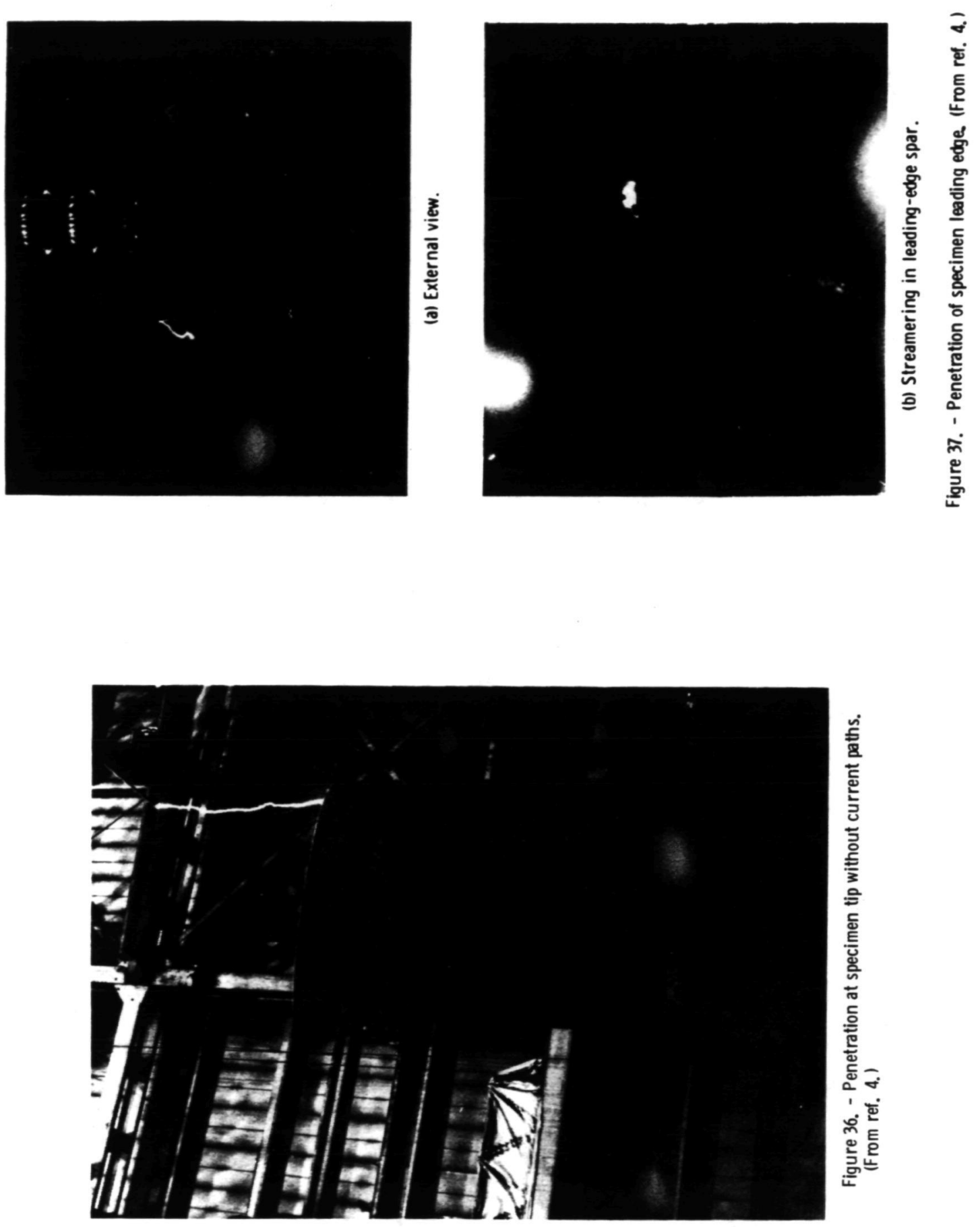


\section{ORIGINAL PAGE \\ BLACK AND WHITE PHOTOGRAPH}

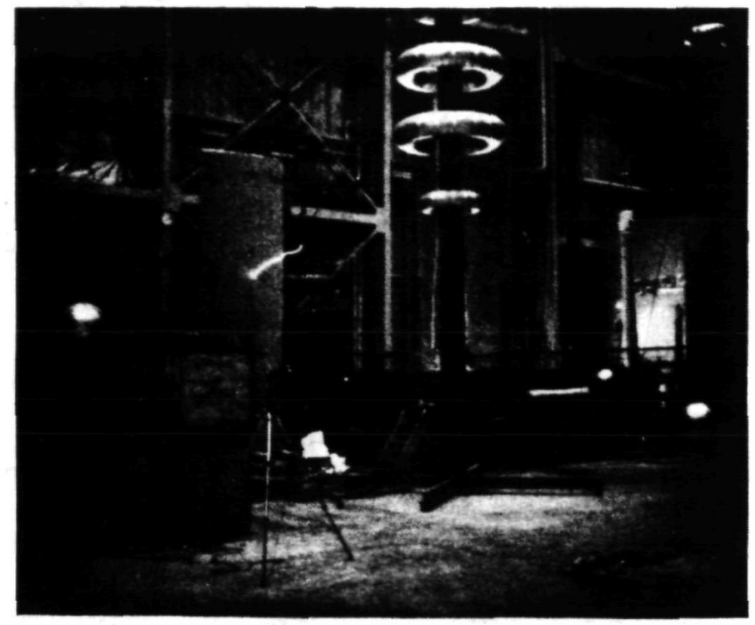

(a) Exterior view.

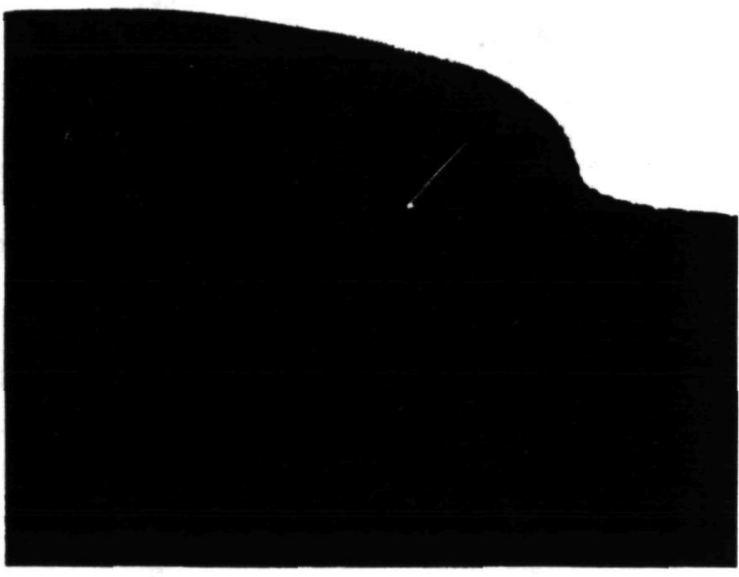

(b) Afterbody panels.

Figure 38. - Internal streamering on penetration of afterbody. (From ref. 4.) 
ORIGINAL PAGE

BLACK AND WHITE PHOTOGRAPH

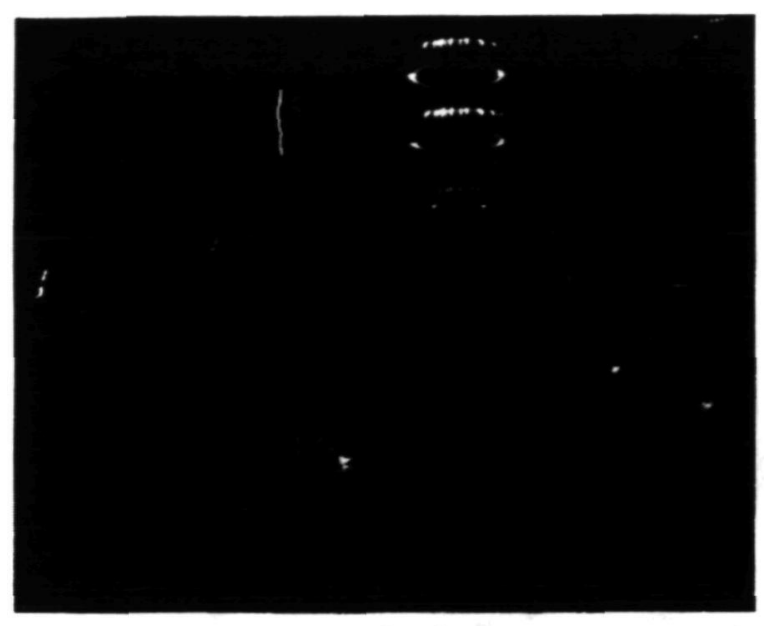

(a) Exterior view.

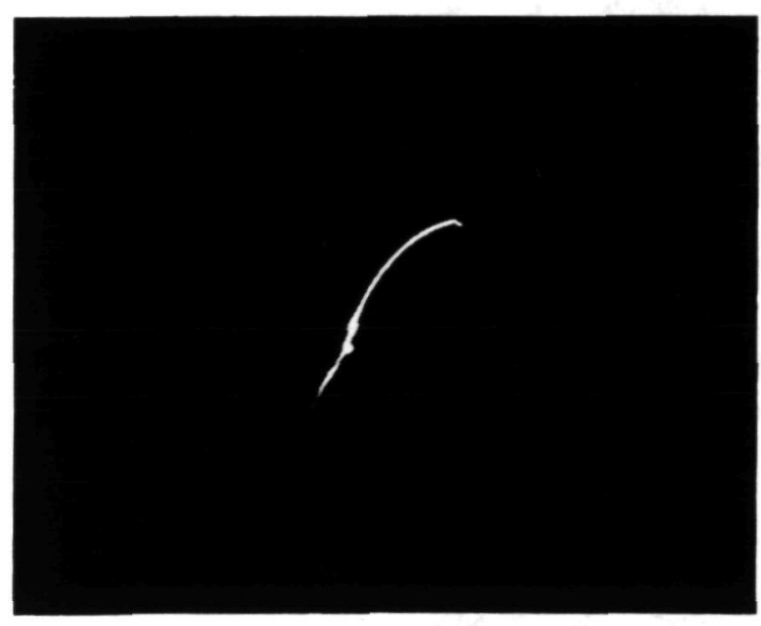

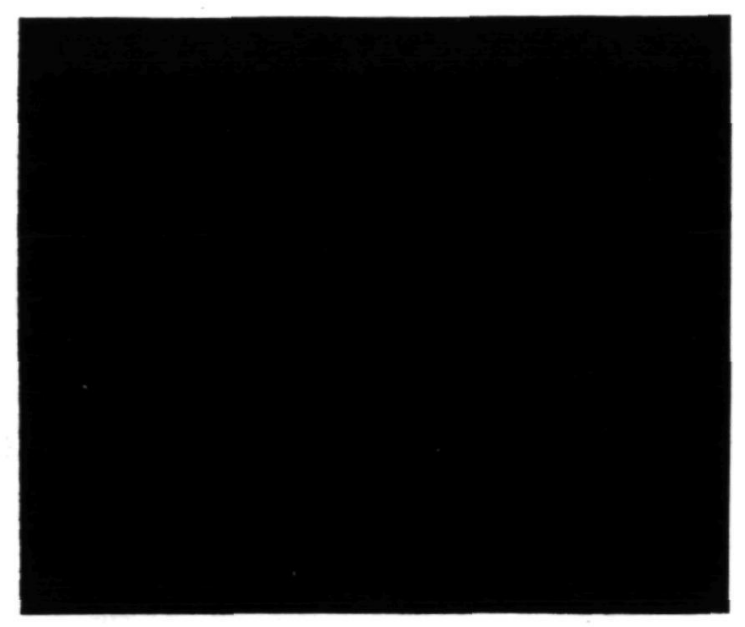

(b) Interior view of afterbody panel.

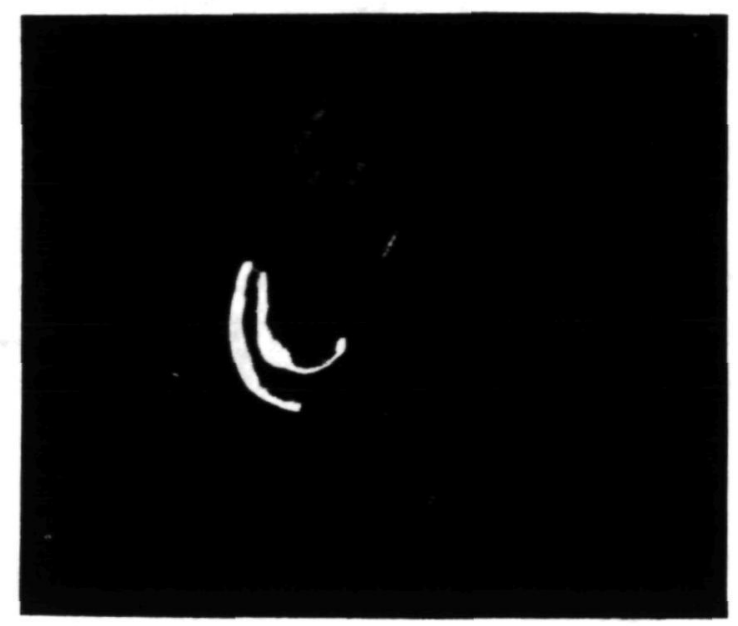

(c) Interior streamering in leading-edge span.

Figure 39. - Penetration of unprotected specimen. (From ref. 4.) 


\section{ORIGINAL PAGE \\ BLACK AND WHITE PHOTOGRAPH}

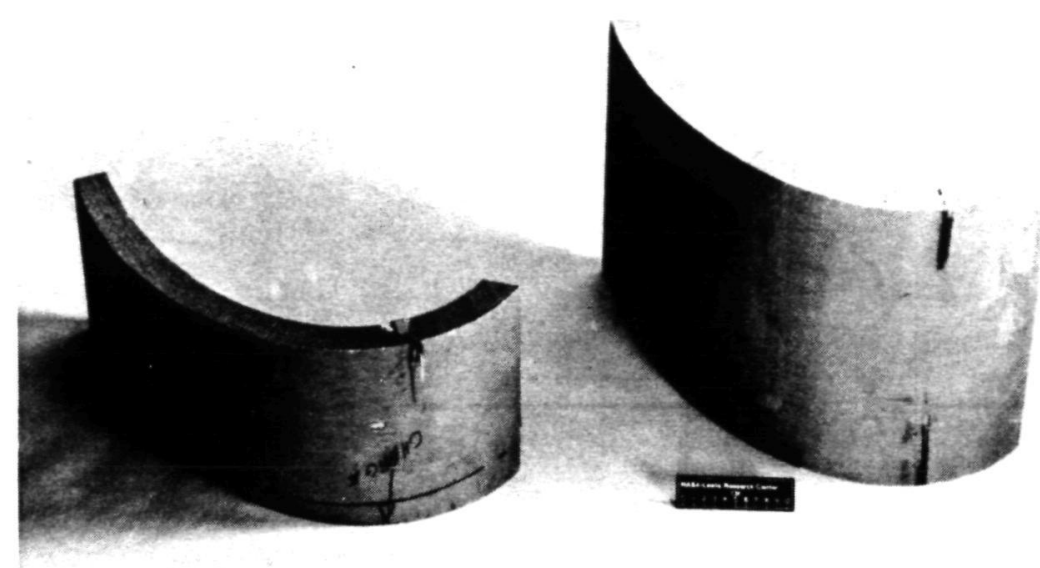

C-80-4993

Figure 40. - External surface view at point of leading-edge penetration. (From ref. 4.)

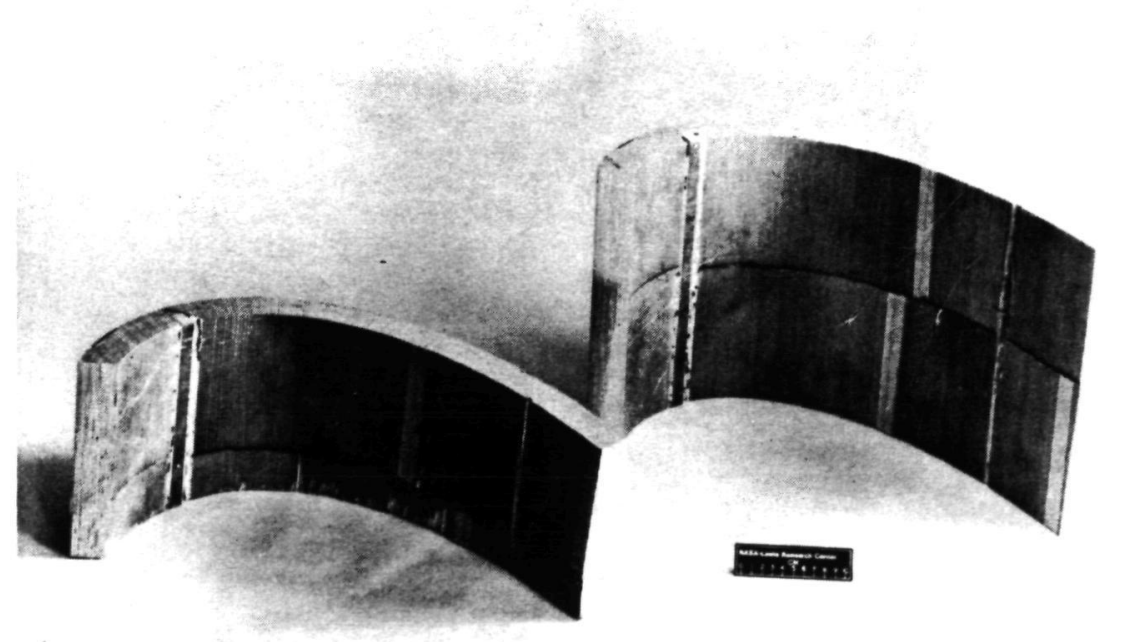

C- $80-4994$

Figure 4l. - Internal surface view at point of leading-edge penetration. (From ref. 4.) 


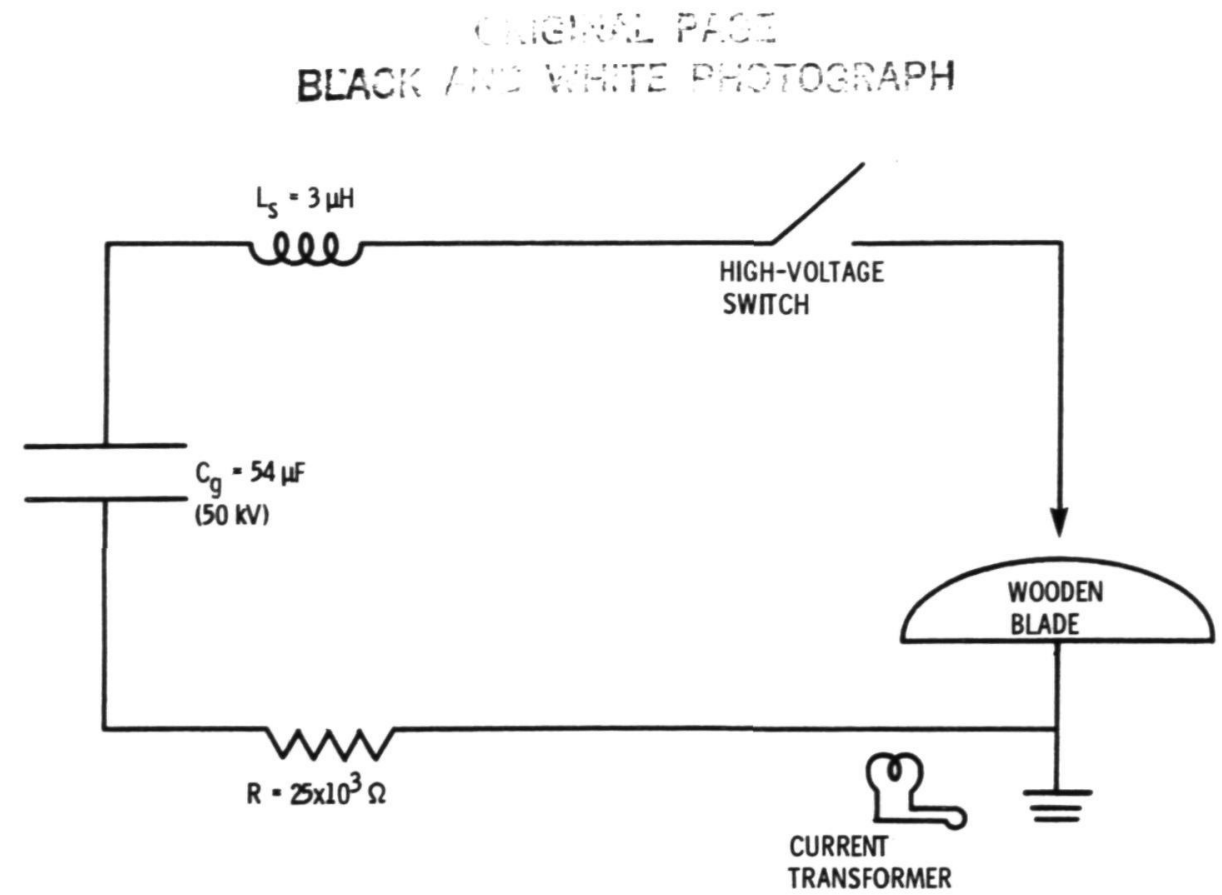

Figure 42 - Test circuit for high-current damage tests. (From ref. 4.)

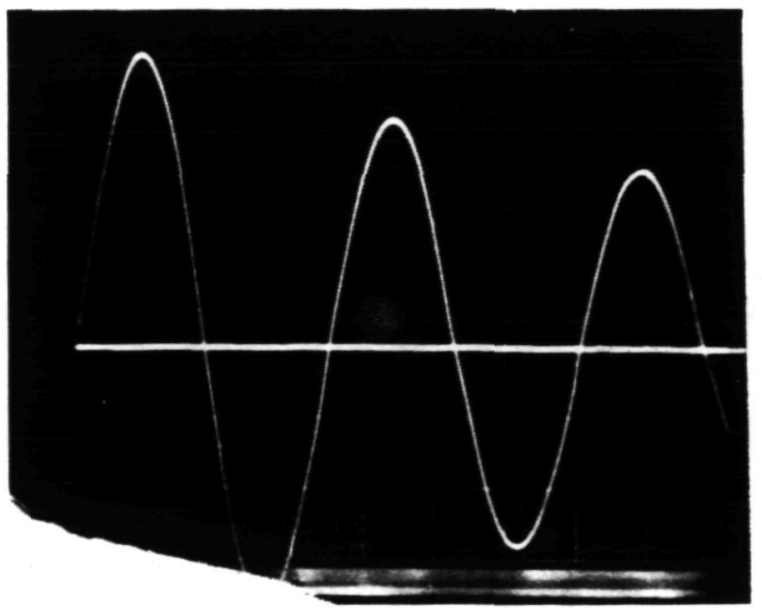

Figure 43. - High-current damage test waveform. (From ref. 4.) 


$$
\begin{gathered}
\text { BEMA PAGE } \\
\text { BLAC: A VIITE PHOTOGRAPH }
\end{gathered}
$$

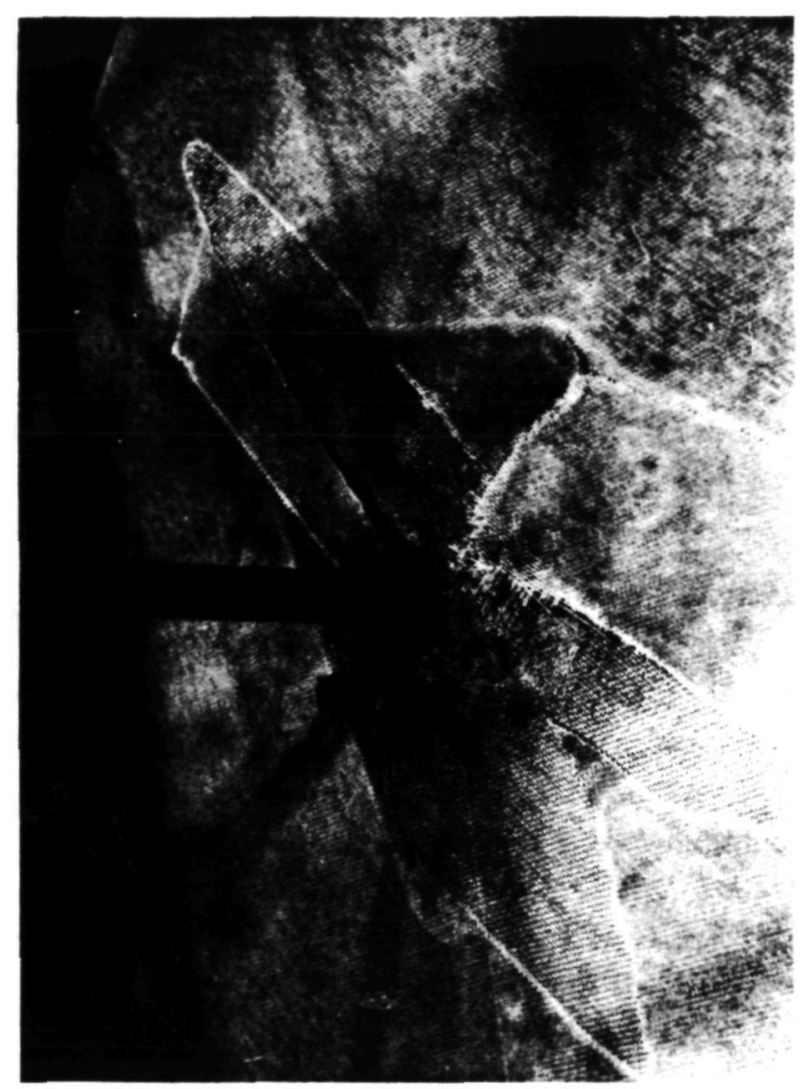

Figure 44. - Aftermath of hign-current passage th rough Nomex afterbody panel. (From ref. 4.). 


\begin{tabular}{|c|c|c|}
\hline 1. F & \multicolumn{2}{|c|}{ 3. Recipient's Catalog No. } \\
\hline \multirow{2}{*}{$\begin{array}{l}\text { 4. Title and Subtitle } \\
\text { EVALUATION OF LIGHTNING ACCOMMODATION SYSTEMS } \\
\text { FOR WIND-DRIVEN TURBINE ROTORS }\end{array}$} & \multicolumn{2}{|c|}{$\begin{array}{l}\text { 5. Report Date } \\
\text { March } 1982\end{array}$} \\
\hline & \multicolumn{2}{|c|}{$\begin{array}{l}\text { 6. Performing Organization Code } \\
776-33-41\end{array}$} \\
\hline \multirow[t]{2}{*}{$\begin{array}{l}\text { 7. Author(s) } \\
\text { H. Bankaitis }\end{array}$} & \multicolumn{2}{|c|}{$\begin{array}{l}\text { 8. Performing Organization Report No. } \\
\text { E-1116 }\end{array}$} \\
\hline & \multicolumn{2}{|l|}{ 10. Work Unit No. } \\
\hline $\begin{array}{l}\text { 9. Performing Organization Name and Address } \\
\text { National Aeronautics and Space Administration }\end{array}$ & \multicolumn{2}{|c|}{ 11. Contract or Grant No. } \\
\hline Cleveland, Ohio 44135 & \multirow{2}{*}{\multicolumn{2}{|c|}{$\begin{array}{l}\text { 13. Type of Report and Period Covered } \\
\text { Technical Memorandum }\end{array}$}} \\
\hline \multirow{2}{*}{$\begin{array}{l}\text { 12. Sponsoring Agency Name and Address } \\
\text { U.S. Department of Energy } \\
\text { Division of Wind Energy Systems } \\
\text { Washington, D.C. } 20545\end{array}$} & & \\
\hline & \multicolumn{2}{|c|}{$\begin{array}{l}\text { 14. Sponsoring Agency Cede Report No } \\
\text { DOE/NASA/20320-37 }\end{array}$} \\
\hline \multicolumn{3}{|c|}{$\begin{array}{l}\text { 15. Supplementary Notes } \\
\text { Final report. Prepared under Int }\end{array}$} \\
\hline \multicolumn{3}{|c|}{$\begin{array}{l}\text { 16. Abstract } \\
\text { Wind-driven turbine generators are being evaluated as an alternative source of electric energy. } \\
\text { Areas of favorable location for the wind-driven turbines (high wind density) coincide with areas } \\
\text { of high incidence of thunderstorm activity. These locations, coupled with the 30-m or larger } \\
\text { diameter rotor blades, make the wind-driven turbine blades probable terminations for lightning } \\
\text { strikes. Several candidate systems of lightning accommodation for composite-structural- } \\
\text { material blades have been designed and their effectiveness evaluated by submitting the systems } \\
\text { to simulated lightning strikes. The test data are analyzed and system designs are reviewed on } \\
\text { the basis of the analysis. The information presented in this report is a compilation of the data } \\
\text { developed by various rotor blade manufacturers and lightning researchers under Department of } \\
\text { Energy sponsorship and NASA Lewis Research Center technical management. }\end{array}$} \\
\hline $\begin{array}{l}\text { 17. } \mathrm{K} \\
\mathrm{L}\end{array}$ & $\begin{array}{l}\text { unlimited } \\
\text { UC } 440\end{array}$ & \\
\hline 19. Se & 21. No. of Pages & 22. Price ${ }^{\circ}$ \\
\hline
\end{tabular}

* For sale by the National Technical Information Service, Springfield, Virginia 22161 